\title{
Root formation and metallurgical challenges in laser beam and laser-arc hybrid welding of thick structural steel
}

\author{
Ivan Bunaziv $^{1}$ - Cato Dørum ${ }^{2} \cdot$ Steen Erik Nielsen ${ }^{3} \cdot$ Pasi Suikkanen $^{4} \cdot$ Xiaobo Ren $^{1} \cdot$ Bård Nyhus $^{1} \cdot$ Magnus Eriksson $^{1}$. \\ Odd M. Akselsen ${ }^{1}$
}

Received: 9 January 2021 / Accepted: 9 June 2021 / Published online: 22 June 2021

(C) The Author(s) 2021

\begin{abstract}
Single-pass laser beam welding (LBW) of steel components with wall thickness of $>10 \mathrm{~mm}$ is of high interest due to enhanced productivity. Deep penetration LBW provides excessive hardness and certain quality issues such as root humping in flat position, which is associated with disability of surface tension to sustain melt dropout. High hardness is associated with fast cooling rates and shortage of filler wire transportation to the root of the fusion zone. Use of laser-arc hybrid welding (LAHW) can promote acicular ferrite by adding filler metal and additional heat input from the arc. However, LAHW may promote humping and adjustment of many parameters is required hindering its application. In this work, a $16 \mathrm{~kW}$ disk laser was used in butt welding of $12 \mathrm{~mm}$ and $15 \mathrm{~mm}$ thick plates with different bevelling geometries. Root humping occurred within a wide range of process parameters providing narrow process window. Twelve millimeter thick plates were successfully welded with a single-pass technique providing good quality of root by using zero air gap regardless bevelling geometry. Welding of $15 \mathrm{~mm}$ plates was more challenging, and the process was sensitive even with a slight parameter change. Improved results were achieved with application of small air gap. Acceptable hardness in both weld metal and heat affected zone $(<290 \mathrm{HV})$ was achieved for both plate thicknesses providing good toughness of minimum $27 \mathrm{~J}$ at $-50^{\circ} \mathrm{C}$.
\end{abstract}

Keywords Laser welding $\cdot$ Hybrid welding $\cdot$ High strength steel $\cdot$ Mechanical properties $\cdot$ Toughness

\section{Introduction}

Steel plates with thickness of $>10 \mathrm{~mm}$ are widely used in a variety of industries like shipbuilding, oil and gas, and construction. Laser beam welding (LBW) and laser-arc hybrid welding (LAHW) are excellent alternative methods to traditional arc welding due to their productivity [1-3]. However, LBW/LAHW may suffer from high hardness [2, 4], root imperfections as humping/sagging due to full penetration mode [5-7], and solidification cracking [8,9], which may result in

Ivan Bunaziv

ivan.bunaziv@sintef.no

1 SINTEF Industry, P.O. Box 4760, Torgarden, NO-7465 Trondheim, Norway

2 Norwegian Public Roads Administration, Bridge Section, Hamar, Norway

3 FORCE Technology, Park Allé 345, DK-2605 Brøndby, Denmark

4 SSAB Europe Oy, Rautaruukintie 155, FI-92100 Raahe, Finland low heat affected zone (HAZ) and weld metal (WM) toughness. Excessive hardness can be mitigated by preheating [2, 10] but it may be expensive and thus should be avoided. Additional heat from the arc as provided in LAHW can assist in high hardness mitigation $[2,11]$. Humping or melt dropping at root is challenging in full penetration single-pass welding case due to $(i)$ complex physics of surface tension forces acting on molten metal and balance with counteracting gravity force, (ii) high temperatures and temperature dependent viscosity of molten metal, (iii) fluctuating pressures inside the keyhole [12-14] affecting keyhole geometry fluctuations [15], and (iv) high molten metal speeds flowing downwards to keyhole exit $[16,17]$. Humping issue in single-pass LBW/ LAHW gained particular interest in recently. Haug et al. [5] demonstrated that after reaching full penetration threshold in $10 \mathrm{~mm}$ carbon steel using autogenous LBW, melt dropping occurred and with subsequent increase laser power, good root quality can be obtained only at specific beam power level with $1 \mathrm{~kW}$ bandwidth. Further increase of laser power led to molten metal ejection from root side and to cutting-like process. Pan et al. [18] showed similar root formation trend and process 
window was expanded by using $\mathrm{CO}_{2}$ shielding gas instead of $\mathrm{Ar}+\mathrm{CO}_{2}$ mixture providing more favorable melt flows to prevent dropping using LAHW. Later, the same phenomenon was noted by Frostevarg [6] and surface tensional forces were identified as the main factor in redirecting melt flow to prevent humping. Moreover, possible reasons more in-depth were discussed with solutions to these challenges. The negative focal point position and faster welding speeds was found to mitigate humping with stably keyhole conditions in LAHW of $12 \mathrm{~mm}$ stainless steel according to Zhang et al. [19]. The recoil pressure, surface tension, and gravity were identified as main forces to be involved in humping development during experimental and numerical studies in single-pass autogenous LBW of $12 \mathrm{~mm}$ thick stainless steel [20]. Tang et al. [21] showed that LAHW using leading arc (laser beam is behind) setup provided less humping due to smaller droplet size and geometry of weld pool reducing ability of surface tension to sustain dropout in case of LAHW of $12 \mathrm{~mm}$ thick carbon steel. As a result, humping is very intricate phenomenon and still not well understood, especially in LAHW due to many parameters involved. Thus, more studies should be done on this issue, especially for thicker than 10 to $12 \mathrm{~mm}$ steel plates.

The present work is a part of the technology qualification for the longest fjord crossing bridge in Norway (called Bjørnafjorden which is $5 \mathrm{~km}$ long), the Ferry Free E39 road. First attempts have been made for butt welds without bevelling of plates in the previous work using 12 and $15 \mathrm{~mm}$ thick steel [22]. It has been shown that optimized parameters by repeating experiments did not provide the same quality over large lengths. This raises a problem of process robustness which is a critical factor for industry. The main two challenges must be resolved which are acceptable geometry of weld shape and microstructure. These both factors affect mechanical properties. The objective of this work is to make systematic variations in welding parameters for two different plate thicknesses with bevelling angles and establish a robust LAHW which can be applied in the prefabrication of bridge components.

The results confirmed that when parameters are optimized, the toughness of the welds is sufficiently high providing minimum $27 \mathrm{~J}$ at low temperature $\left(-50^{\circ} \mathrm{C}\right)$. Hardness values were lower than $290 \mathrm{HV}$ for $12 \mathrm{~mm}$ thick plates and $310 \mathrm{HV}$ for $15 \mathrm{~mm}$ thick plates, respectively. Humping-free welds were much easier to obtain for $12 \mathrm{~mm}$ than for $15 \mathrm{~mm}$ thick plates where humping was persistent even using small root face (3 $\mathrm{mm}$ ) with bevelling. Robust process parameters were established with consistent quality over significant length. Application of air gap in case of $15 \mathrm{~mm}$ thick was positive in reducing humping as well as larger laser-arc interdistance. As a result, $12 \mathrm{~mm}$ thick plates can be successfully joined with the use of LAHW as tandem process with single-pass technique offering improved productivity with good mechanical properties. Fifteen millimeter thick plates still are challenging to join and further optimization of process parameters and groove re-design is required.

\section{Methodology}

\subsection{Materials}

The steel plates were 12 and $15 \mathrm{~mm}$ in thickness and cut to dimensions of $500 \mathrm{~mm} \times 150 \mathrm{~mm}$. The base metal $(\mathrm{BM})$ is thermomechanically rolled steel with banded ferrite-pearlite microstructure providing toughness of $40 \mathrm{~J}$ at $-60^{\circ} \mathrm{C}$. A commercial $1.2 \mathrm{~mm}$ solid wire was selected, Mn-Si-alloyed G4Si1 wire according to ISO 14341 [23]. The steel and filler wire chemical compositions are outlined in Table 1 . The base plate $P_{c m}$ carbon equivalent value is $0.25\left(P_{c m}<0.14 \mathrm{wt} . \% \mathrm{C}, P_{c m}=\right.$ $\mathrm{C}+\mathrm{Si} / 30+(\mathrm{Mn}+\mathrm{Cu}+\mathrm{Cr}) / 20+\mathrm{Ni} / 60+\mathrm{Mo} / 15+\mathrm{V} / 10+$ $5 \mathrm{~B})$, while the $\mathrm{CE}_{\mathrm{IIW}}$ equivalent is $0.41\left(C E_{I I W}\right.$ for low alloy steels, $\left.C E_{I I W}=\mathrm{C}+\mathrm{Mn} / 6+(\mathrm{Cr}+\mathrm{Mo}+\mathrm{V}) / 5+(\mathrm{Cu}+\mathrm{Ni}) / 15\right)$ representing good weldability.

The base metal has minimum specified yield strength of $420 \mathrm{MPa}\left(R_{p 0.2}\right)$ and ultimate tensile strength of $520-680 \mathrm{MPa}$ $\left(R_{m}\right)$. The solid filler wire provides yield and tensile strength of 420-460 MPa and 500-680 MPa, respectively.

\subsection{Equipment and setup}

A continuous wave $16 \mathrm{~kW}$ disk laser (TruDisk 16002 TRUMPF) with random polarization was used with $200 \mu \mathrm{m}$ fiber core diameter, $8 \mathrm{~mm} \cdot \mathrm{mrad}$ beam parameter product $(B P P)$, and $1030 \mathrm{~nm}$ wavelength. The focal length was $600 \mathrm{~mm}$ and the spot size of $300 \mu \mathrm{m}$ in diameter (as measured). The welding setup is shown in Fig. 1. The laser beam had inclination angle of $7^{\circ}$ from normal to eliminate high back reflections. A gas metal arc welding (GMAW) torch was tilted by $75^{\circ}$ from the welding surface. The welds were deposited with an articulated robot. The filler wire stick-out was $20 \pm 2$ $\mathrm{mm}$, and the shielding gas composition was $80 \% \mathrm{Ar}+20 \%$ $\mathrm{CO}_{2}$ for LAHW and pure Ar for LBW with the flow rate of 25 $1 / \mathrm{min}$.

Two different Y-shaped bevelling geometries were used as shown in Fig. 2. LBW and LAHW were used for the root, and

Table 1 Chemical composition (wt.\%) of base metal and wire

\begin{tabular}{lllllll}
\hline Material & $\mathrm{C}$ & $\mathrm{Si}$ & $\mathrm{Mn}$ & $\mathrm{P}$ & $\mathrm{S}$ & $\mathrm{Fe}$ \\
\hline Base metal1 & 0.14 & 0.50 & 1.60 & 0.020 & 0.015 & Bal. \\
Wire2 & 0.10 & 1.00 & 1.70 & 0.025 & 0.025 & Bal. \\
\hline $\begin{array}{l}{ }^{1} \text { Mill certificate values, small amounts of Nb, V, and Ti (<0.05 wt. \%) are } \\
\text { present } \\
{ }^{2} \text { Nominal values according to manufacturer's datasheet }\end{array}$ & &
\end{tabular}




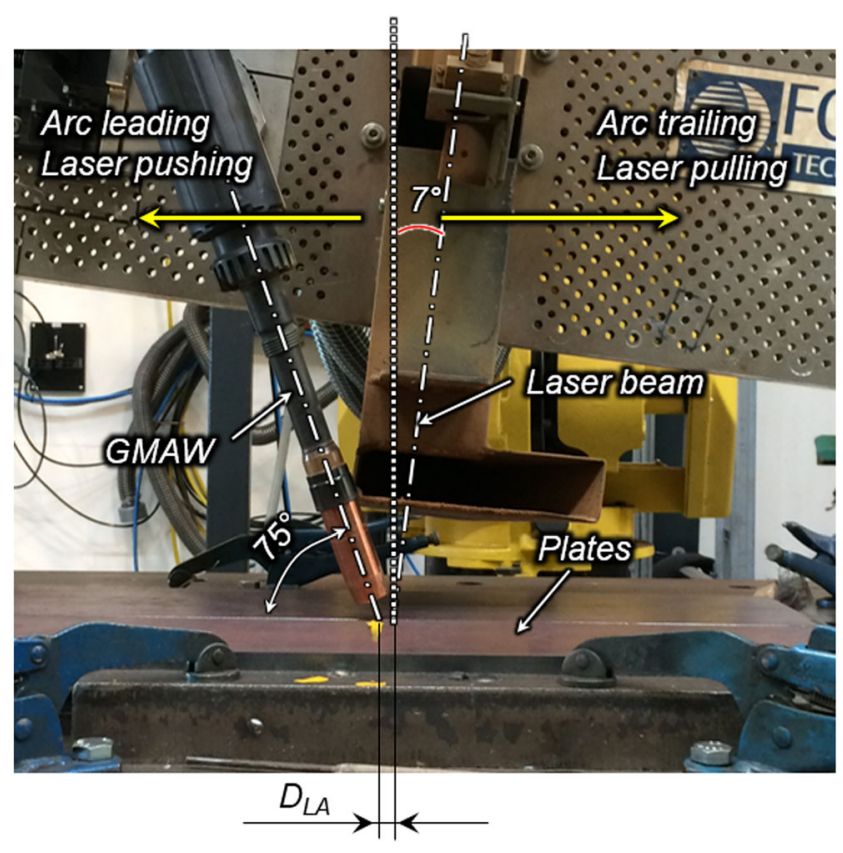

Fig. 1 Experimental welding setup

filling pass (second upper layer) as made by LAHW using lower beam power. A spray droplet transfer mode (nonpulsed) was chosen. Machined edges were used with fine surface quality, surface roughness $\left(R_{a}\right)$ of $0.8 \mu \mathrm{m}$. Run-in and run-out plates were tack welded to the plates to keep the air gap constant. The sidewalls were cleaned with acetone to remove grease prior to welding.

\subsection{Process variables}

The main variables were laser beam power $\left(P_{L}\right)$, welding speed $\left(v_{s}\right)$, laser-arc distance $\left(D_{L A}\right)$, wire feed rate $(W F R)$, focal point position $(F P P)$, air gap, and arc position $(A P)$.
Calculation formula of heat inputs $\left(Q_{L}\right.$ for the laser, $Q_{A}$ for the arc, $Q_{H}$ for the LAHW) can be found in [9]. LAHW has a vast amount of welding parameters; thus, performing full factorial experiments is very costly. With each experimental run, one variable was adjusted subsequently. In this way, fewer experiments are needed. The $F P P$, as the main process parameter, was initially changed dynamically over a certain length providing very efficient method to understand its effect.

The employed process parameters for $20^{\circ}$ and $10^{\circ} \mathrm{Y}$ bevelling for $12 \mathrm{~mm}$ thick plates are outlined in Tables 2 and 3 , respectively. In the case of $15 \mathrm{~mm}$ thick plates, parameters for $20^{\circ}$ and $10^{\circ} \mathrm{Y}$-bevelling are shown in Tables 4 and 5 , respectively.

\subsection{Mechanical properties testing and metallurgical characterization}

The Charpy impact toughness test was performed according to ISO 9016 [24] with standard specimen dimensions of $55 \times 10 \times 10 \mathrm{~mm}^{3}$ and $\mathrm{V}$-notch type geometry. Three test series were included; $(i)$ the notch located at the weld metal (WM) center covering both the arc and laser zones, and (ii) the fusion line (FL) of the laser zone (where the fusion line is straight and nearly perpendicular to the plate thickness direction). The samples were cut transverse to the welding direction with the parallel fracture path. All tests were performed at -50 ${ }^{\circ} \mathrm{C}$, using three parallels for each notch position. The locations of extracted specimens with the V-notch positions are shown in Fig. 3. The placement of the V-notch is challenging in case of FL. Therefore, etching was performed before placement of the notch.

Metallographic studies were performed according to the ISO 17639 [25] standard. Etching was carried out in a $2 \%$ nital solution for $5 \mathrm{~s}$. Macrographs were examined with optical microscope for microstructure characterization.

Fig. 2 Bevelling of grooves: a $20^{\circ}$ bevelling angle in total with $6 \mathrm{~mm}$ root face $(1 . X$ series $)$; b $10^{\circ}$ bevelling angle in total with $3 \mathrm{~mm}$ root face ( $2 . X$ series); $\mathbf{c} 20^{\circ}$ bevelling angle in total with $6 \mathrm{~mm}$ root face (3.X series); and $\mathbf{d} 10^{\circ}$ bevelling angle in total with $3 \mathrm{~mm}$ root face (4.X series)

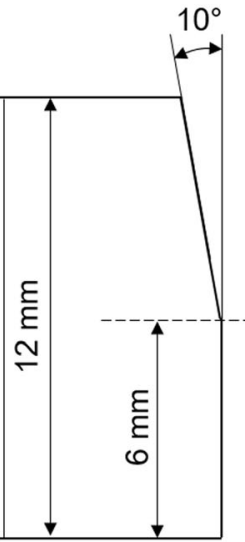

(a)

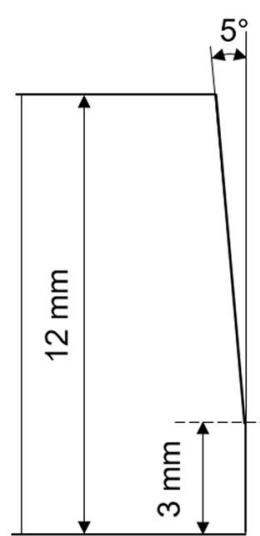

(b)

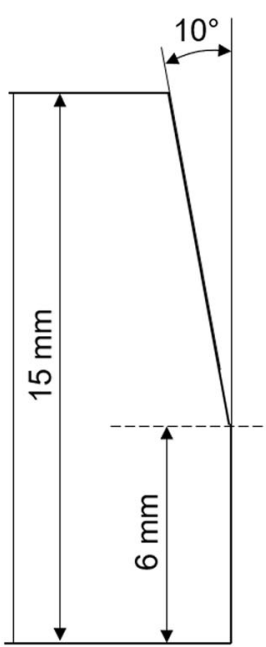

(c)

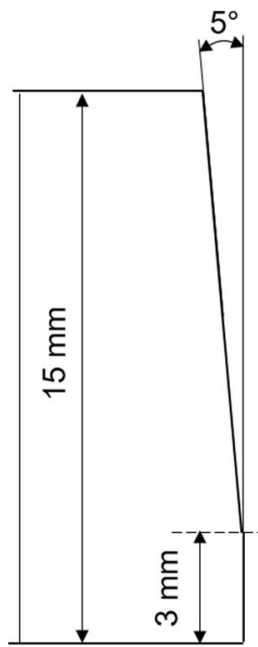

(d) 
Table 2 Welding parameters for $12 \mathrm{~mm}$ thick plates with $20^{\circ}$ bevelling angle. $P L$ is laser pulling. Air gap was constant at 0 mm

\begin{tabular}{|c|c|c|c|c|c|c|c|c|c|}
\hline \multirow[t]{2}{*}{ Weld no. } & \multirow[t]{2}{*}{ Laser power $(\mathrm{kW})$} & \multirow[t]{2}{*}{ Welding speed $v_{s}(\mathrm{~m} / \mathrm{min})$} & \multirow[t]{2}{*}{$D_{L A}(\mathrm{~mm})$} & \multirow[t]{2}{*}{ Arc position } & \multirow[t]{2}{*}{$W F R(\mathrm{~m} / \mathrm{min})$} & \multirow[t]{2}{*}{$F P P(\mathrm{~mm})$} & \multicolumn{3}{|c|}{ Heat input $(\mathrm{kJ} / \mathrm{mm})$} \\
\hline & & & & & & & $Q_{L}$ & $Q_{A}$ & $Q_{H}$ \\
\hline $1 . \mathrm{T} 1$ & 12 & 1.0 & - & $P L$ & - & $0 \rightarrow+50$ & 0.50 & - & 0.50 \\
\hline $1 . \mathrm{T} 2$ & 16 & 1.5 & - & $P L$ & - & $0 \rightarrow+50$ & 0.45 & - & 0.45 \\
\hline 1.1 & 16 & 1.5 & - & $P L$ & - & +30 & 0.45 & - & 0.45 \\
\hline Fill1 & 3 & 0.5 & 15 & Trailing & 9.0 & +30 & 0.25 & 0.78 & 1.03 \\
\hline 1.2 & 16 & 1.5 & 15 & Trailing & 8.0 & +30 & 0.45 & 0.20 & 0.64 \\
\hline 1.3 & 16 & 1.5 & 30 & Trailing & 16.0 & +30 & 0.45 & 0.46 & 0.91 \\
\hline 1.4 & 16 & 1.5 & 30 & Trailing & 16.0 & +30 & 0.45 & 0.50 & 0.95 \\
\hline
\end{tabular}

${ }^{1}$ LAHW was used as second pass for filling material to provide a slight reinforcement on top

Measurements of Vickers microhardness $\left(\mathrm{HV}_{0.5}\right)$ were conducted with a $500 \mathrm{gf}$ load according to the ISO 22826 [26] standard.

\section{Results and discussion}

\subsection{Welding of $12 \mathrm{~mm}$ thick plates}

\subsubsection{Welds with $20^{\circ}$ bevelling angle}

Preliminary experiments were performed with variation of the focal point position from $0 \mathrm{~mm}$ (the smallest spot diameter of $300 \mu \mathrm{m}$ was located on plate surface) to $+50 \mathrm{~mm}$ (defocused laser beam with larger spot diameter) by using autogenous LBW (without arc). Initially, a laser beam power of $12 \mathrm{~kW}$ and welding speed of $1.0 \mathrm{~m} / \mathrm{min}$ were chosen (Weld No. 1.T1). The root appearance is shown in Fig. 4. For an FPP value between 0 and $5 \mathrm{~mm}$, there is strong melt ejections due to excessive laser power intensity. Good root quality was achieved at a defocusing distance of 15-25(+) mm. At larger defocusing distances $(F P P>30 \mathrm{~mm})$, the humping and then the lack of penetration (at $F P P \approx 40 \mathrm{~mm}$ ) occur due to larger spot diameter at the surface, and thus lower power intensity. This trend agrees with other researchers $[6,18,27]$. There is a possible process window, characterized by a smooth root appearance with a slight reinforcement, when there is a balance between laser power and FPP to obtain full penetration and the occurrence of melt ejections. The process physics with explanations is shown in Fig. 5.

To increase productivity, the laser power was increased to $16 \mathrm{~kW}$ with welding speed of $1.5 \mathrm{~m} / \mathrm{min}$; see Fig. 6 (Weld No. 1.T2). High root quality was produced at a defocused distance (or FPP) of $20-30 \mathrm{~mm}$. Considering that it provides $50 \%$ increase in productivity, the remaining experiments were performed at $+30 \mathrm{~mm}$ focal point position using the same welding speed of $1.5 \mathrm{~m} / \mathrm{min}$. Large defocusing distance was used due to extensive focal length and small spot diameter of the used disk laser having low BPP (see Section 2.2).

The experiment with $+30 \mathrm{~mm}$ focal position was repeated for welding of $0.5 \mathrm{~m}$ long plates and the root appearance is shown in Fig. 7 (Weld No. 1.1). The root had inconsistent quality with strong melt ejections in the beginning of the weld. A good root was formed in the second part of the plate. Such behavior might be related to variation of air gap between the plates or process stabilization issues. Thus, run-in and run-out plates should be used to avoid such conditions.

Single-pass LAHW was applied with the same parameters as Weld No. 1.1, using $16 \mathrm{~kW}$ and with $8 \mathrm{~m} / \mathrm{min} W F R$ (wire feed rate) with trailing arc configuration (15 $\mathrm{mm} D_{L A}$ ) (see Fig. 1 for terminology). A strong humping was observed because of the arc influence on process stability; see Fig. 7 (Weld No. 1.2). This is related to unfavorable effect on melt

Table 3 Welding parameters for $12 \mathrm{~mm}$ thick plates with $10^{\circ}$ bevelling angle. $P L$ is laser pulling

Weld no. Laser power $(\mathrm{kW})$ Welding speed $v_{S}(\mathrm{~m} / \mathrm{min}) \quad D_{L A}(\mathrm{~mm})$ Arc position $W F R(\mathrm{~m} / \mathrm{min})$ Air gap (mm) $F P P(\mathrm{~mm}) \quad H$ Heat input $(\mathrm{kJ} / \mathrm{mm})$

\begin{tabular}{|c|c|c|c|c|c|c|c|c|c|c|}
\hline 2.T1 & 16 & 1.5 & - & $P L$ & - & 0.0 & $0 \rightarrow+50$ & 0.45 & - & 0.45 \\
\hline 2.T2 & 16 & 2.0 & - & $P L$ & - & 0.4 & $0 \rightarrow+50$ & 0.34 & - & 0.34 \\
\hline 2.1 & 16 & 1.5 & 30 & Trailing & 16.0 & 0.0 & +30 & 0.45 & 0.46 & 0.91 \\
\hline 2.2 & 16 & 1.5 & 30 & Trailing & 20.0 & 0.0 & +30 & 0.45 & 0.53 & 0.98 \\
\hline 2.3 & 16 & 1.5 & 30 & Trailing & 20.0 & 0.0 & +30 & 0.45 & 0.53 & 0.98 \\
\hline
\end{tabular}


Table 4 Welding parameters for $15 \mathrm{~mm}$ thick plates with $20^{\circ}$ bevelling angle

\begin{tabular}{|c|c|c|c|c|c|c|c|c|c|c|}
\hline \multirow{2}{*}{$\begin{array}{l}\text { Weld } \\
\text { no. }\end{array}$} & \multirow{2}{*}{$\begin{array}{l}\text { Laser } \\
\text { power } \\
(\mathrm{kW})\end{array}$} & \multirow{2}{*}{$\begin{array}{l}\text { Welding } \\
\text { speed } v_{s} \\
(\mathrm{~m} / \mathrm{min})\end{array}$} & \multirow{2}{*}{$\begin{array}{l}D_{L A} \\
(\mathrm{~mm})\end{array}$} & \multirow{2}{*}{$\begin{array}{l}\text { Arc } \\
\text { position }\end{array}$} & \multirow{2}{*}{$\begin{array}{l}\text { WFR } \\
(\mathrm{m} / \mathrm{min})\end{array}$} & \multirow{2}{*}{$\begin{array}{l}\text { Air } \\
\text { gap } \\
(\mathrm{mm})\end{array}$} & \multirow{2}{*}{$\begin{array}{l}F P P \\
(\mathrm{~mm})\end{array}$} & \multicolumn{3}{|c|}{ Heat input $(\mathrm{kJ} / \mathrm{mm})$} \\
\hline & & & & & & & & $Q_{L}$ & $Q_{A}$ & $Q_{H}$ \\
\hline 3.1 & 7 & 1.5 & 5 & Trailing & 4.0 & 0.0 & 0 & 0.20 & 0.09 & 0.29 \\
\hline 3.2 & 10 & 1.5 & 5 & Trailing & 4.0 & 0.0 & 0 & 0.28 & 0.09 & 0.37 \\
\hline 3.3 & 10 & 1.5 & 15 & Trailing & 4.0 & 0.0 & 0 & 0.28 & 0.09 & 0.37 \\
\hline 3.4 & 10 & 1.5 & 5 & Trailing & 4.02 & 0.0 & 0 & 0.28 & 0.09 & 0.37 \\
\hline 3.5 & 7 & 1.5 & 5 & Leading & 8.0 & 0.4 & 0 & 0.20 & 0.20 & 0.40 \\
\hline 3.6 & 7 & 2.0 & 5 & Leading & 10.0 & 0.4 & 0 & 0.15 & 0.24 & 0.38 \\
\hline 3.7 & 10 & 2.0 & 5 & Leading & 10.0 & 0.4 & 0 & 0.21 & 0.24 & 0.45 \\
\hline Fill1 & 3 & 0.5 & 5 & Trailing & 10.0 & fill & 0 & 0.25 & 0.95 & 1.20 \\
\hline 3.8 & 11 & 2.0 & 5 & Leading & 10.0 & 0.4 & 0 & 0.23 & 0.24 & 0.47 \\
\hline Fill1 & 3 & 0.5 & 5 & Trailing & 10.0 & fill & 0 & 0.25 & 0.95 & 1.20 \\
\hline 3.9 & 16 & 1.0 & 15 & Trailing & 4.0 & 0.0 & +42 & 0.67 & 0.14 & 0.81 \\
\hline 3.10 & 16 & 1.0 & 15 & Trailing & 2.0 & 0.0 & +42 & 0.67 & 0.06 & 0.74 \\
\hline 3.11 & 16 & 1.2 & 15 & Trailing & 2.0 & 0.0 & +42 & 0.56 & 0.05 & 0.61 \\
\hline 3.12 & 16 & 1.4 & 15 & Trailing & 2.0 & 0.0 & +42 & 0.48 & 0.05 & 0.53 \\
\hline
\end{tabular}

${ }^{1}$ LAHW was used as second pass for filling material to provide a slight reinforcement on top

${ }^{2}$ Pulsed arc was used to test its effect on humping flows providing strong momentum in the root [22] with poor process control due to keyhole instability. The same parameters were repeated for another $0.5 \mathrm{~m}$ long plate with significant adjustments in WFR reaching $16 \mathrm{~m} / \mathrm{min}$ to form larger weld reinforcement. Moreover, larger laser-arc separation distance (30 $\mathrm{mm} D_{L A}$ ) was applied to reduce arc and laser beam interaction. As a result, good root quality was produced; see Fig. 7 (Weld No. 1.3). Considering high welding speed (1.5 m/min) in single-pass was applied, this could be a good potential for high productivity enhancement. However, the weld cap had poor quality with spattering due to unstable arc since the arc welding may not work at such high welding speeds. The typical welding speed for GMAW is $0.3-0.5 \mathrm{~m} / \mathrm{min}$ depending on required WFR. Experiment was repeated and almost identical root quality was achieved (see Fig. 7, Weld No. 1.4) except two sporadic humps occurred in the end of weld. Thus, careful assessment of welds should be performed in production.

\subsubsection{Welds with $10^{\circ}$ bevelling angle}

For Y-bevelling with $10^{\circ}\left(20^{\circ}\right.$ in total) angle, the same LBW parameters $(16 \mathrm{~kW}$ power) as Weld No. 1.T2 were applied with dynamic variation in the focal point distance; see Fig. 8 (Weld No. 2.T1). The root had good quality at similar defocusing distance, 25-30(+) mm. Compared to Weld No. 1.T2, high quality root was achieved at longer defocusing distances.

In case of $3 . X$ series, the root face was $3 \mathrm{~mm}$ (instead of $6 \mathrm{~mm}$ as for $1 . X$ series); thus, less material needs to be penetrated. Therefore, it is reasonable to increase the welding speed even further. A slight air gap was also employed to ensure full penetration depth. The root appearance is shown in Fig. 9 (Weld No. 2.T2). Poor root quality was achieved at any defocusing distance. This indicates that air gap did not provide benefits for autogenous LBW and adversely affected root quality due to instability related to lack of metal.
Table 5 Welding parameters for $15 \mathrm{~mm}$ thick plates with $10^{\circ}$ bevelling angle, air gap $=0.0 \mathrm{~mm}$, and $F P P=0 \mathrm{~mm}$ as constant parameters

\begin{tabular}{|c|c|c|c|c|c|c|c|c|}
\hline \multirow{2}{*}{$\begin{array}{l}\text { Weld } \\
\text { no. }\end{array}$} & \multirow{2}{*}{$\begin{array}{l}\text { Laser power } \\
(\mathrm{kW})\end{array}$} & \multirow{2}{*}{$\begin{array}{l}\text { Welding speed } v_{s} \\
(\mathrm{~m} / \mathrm{min})\end{array}$} & \multirow{2}{*}{$\begin{array}{l}D_{L A} \\
(\mathrm{~mm})\end{array}$} & \multirow{2}{*}{$\begin{array}{l}\text { Arc } \\
\text { position }\end{array}$} & \multirow{2}{*}{$\begin{array}{l}\text { WFR } \\
(\mathrm{m} / \mathrm{min})\end{array}$} & \multicolumn{3}{|c|}{ Heat input $(\mathrm{kJ} / \mathrm{mm})$} \\
\hline & & & & & & $Q_{L}$ & $Q_{A}$ & $Q_{H}$ \\
\hline 4.1 & 12 & 1.5 & 10 & - & - & 0.34 & - & 0.34 \\
\hline 4.2 & 12 & 1.5 & 10 & Leading & 2.0 & 0.34 & 0.04 & 0.38 \\
\hline 4.3 & 10 & 1.5 & 10 & Leading & 2.0 & 0.28 & 0.04 & 0.32 \\
\hline 4.4 & 10 & 1.5 & 10 & Trailing & 2.0 & 0.28 & 0.04 & 0.32 \\
\hline 4.5 & 10 & 1.5 & 5 & Trailing & 4.0 & 0.28 & 0.09 & 0.37 \\
\hline 4.6 & 7 & 1.5 & 5 & Trailing & 4.0 & 0.20 & 0.09 & 0.29 \\
\hline
\end{tabular}


Fig. 3 Extraction of Charpy specimens and V-notch location for $\mathbf{a} 12 \mathrm{~mm}$ thick steel and $\mathbf{b}$ $15 \mathrm{~mm}$ thick steel

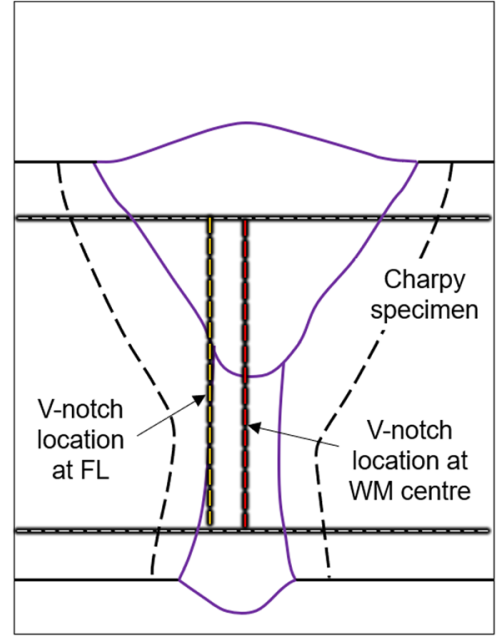

(a)

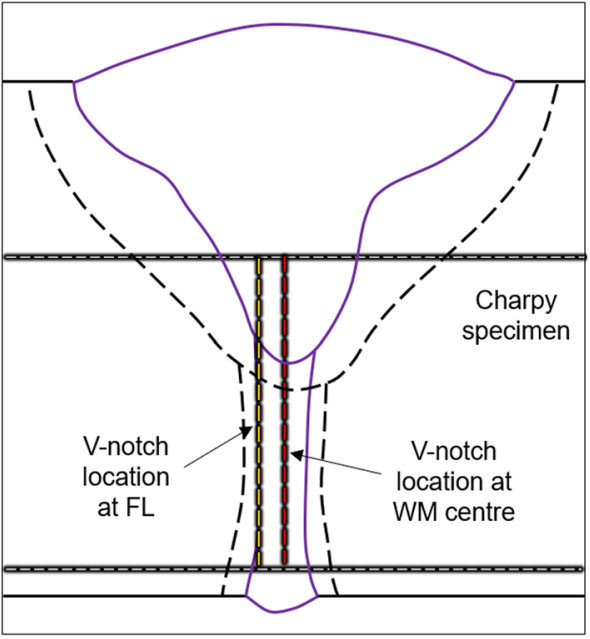

(b)
Since better root quality was provided with zero air gap and slower travel speed $(1.5 \mathrm{~m} / \mathrm{min})$, the same parameter set was applied for welding full length of plates $(0.5 \mathrm{~m})$ with arc having $16 \mathrm{~m} / \mathrm{min}$ WFR; see Fig. 10 (Weld No. 2.1). Inconsistent root quality was produced with severe melt ejection process in the beginning of weld which is related to the absence of the arc source (trailing arc with $30 \mathrm{~mm} D_{L A}$ ). Hereafter, good root quality with reinforcement was produced. This might be related to mass balance during transient welding, where higher portion of the molten metal is pushed forward to the end of the weld. This clearly proves that run-in and run-out plates are compulsory in production to eliminate these problems. Still, the weld cap had stability issues with spattering due to nonoptimized arc source parameters. An increase of the WFR may provide more stable condition.

For the next experimental runs, the weld is conducted with the same parameters to test the reproducibility with slightly increased arc WFR (to $20 \mathrm{~m} / \mathrm{min}$ ); see Fig. 10 (both Weld No. 2.2 and 2.3). The root quality had better consistency regarding the start and end of the weld, with a slight root reinforcement. Note that a slight WFR increase produced less spattering on weld cap.

\subsection{Welding of $15 \mathrm{~mm}$ thick plates}

\subsubsection{Welds with $20^{\circ}$ bevelling angle}

The initial experiments were conducted with lower beam power of $7 \mathrm{~kW}, 1.5 \mathrm{~m} / \mathrm{min}$ welding speed, and trailing arc with $4 \mathrm{~m} / \mathrm{min} W F R$. Incomplete penetration occurred due to low beam intensity. Full penetration was achieved with $10 \mathrm{~kW}$ laser power with some humping; see Fig. 11, Weld No. 3.2. Short laser-arc distance $(5 \mathrm{~mm})$ had negative effect on weld pool stability generating high flow velocity promoting humping. Subsequently, laser-arc distance was increased from 5 to $15 \mathrm{~mm}$. Full penetration was achieved with some spattering in the root due to strong melt ejections (Fig. 11, Weld No. 3.3). On top, the wire melting process was unstable resulting in poor quality of weld cap. The same parameters as for Weld No. 3.2 were applied but with pulsed arc, but no improvement in quality was achieved; see Fig. 11 (Weld No. 3.4). It seems that the laser power $(10 \mathrm{~kW})$ was too high for the present case with small root face of $3 \mathrm{~mm}$ and $0 \mathrm{~mm} F P P$. A reduction in the laser power will inevitably produce humping (see Fig. 5).

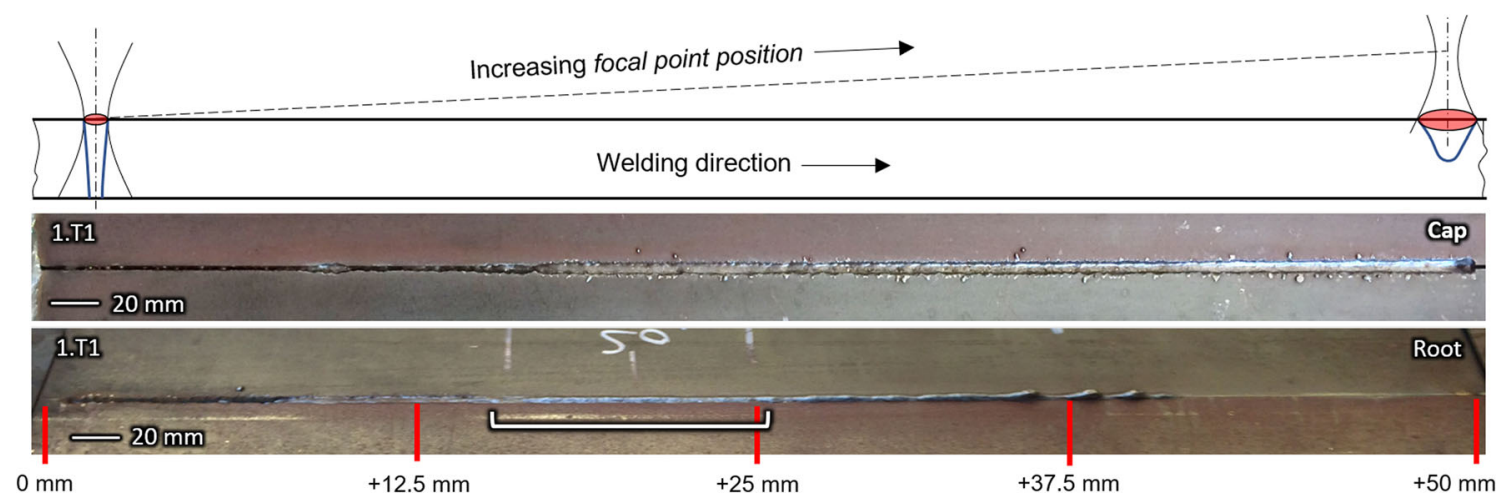

Fig. 4 Weld seam appearances of Weld No. $1 . \mathrm{T} 1$ with dynamic variation of focal point position. Constant parameters: $P_{L}=12 \mathrm{~kW}, v_{s}=1.0 \mathrm{~m} / \mathrm{min}$, and $0.0 \mathrm{~mm}$ air gap 
Fig. 5 Root formation modes (bandwidth) with different laser beam intensity controlled by dynamic focal point position variation

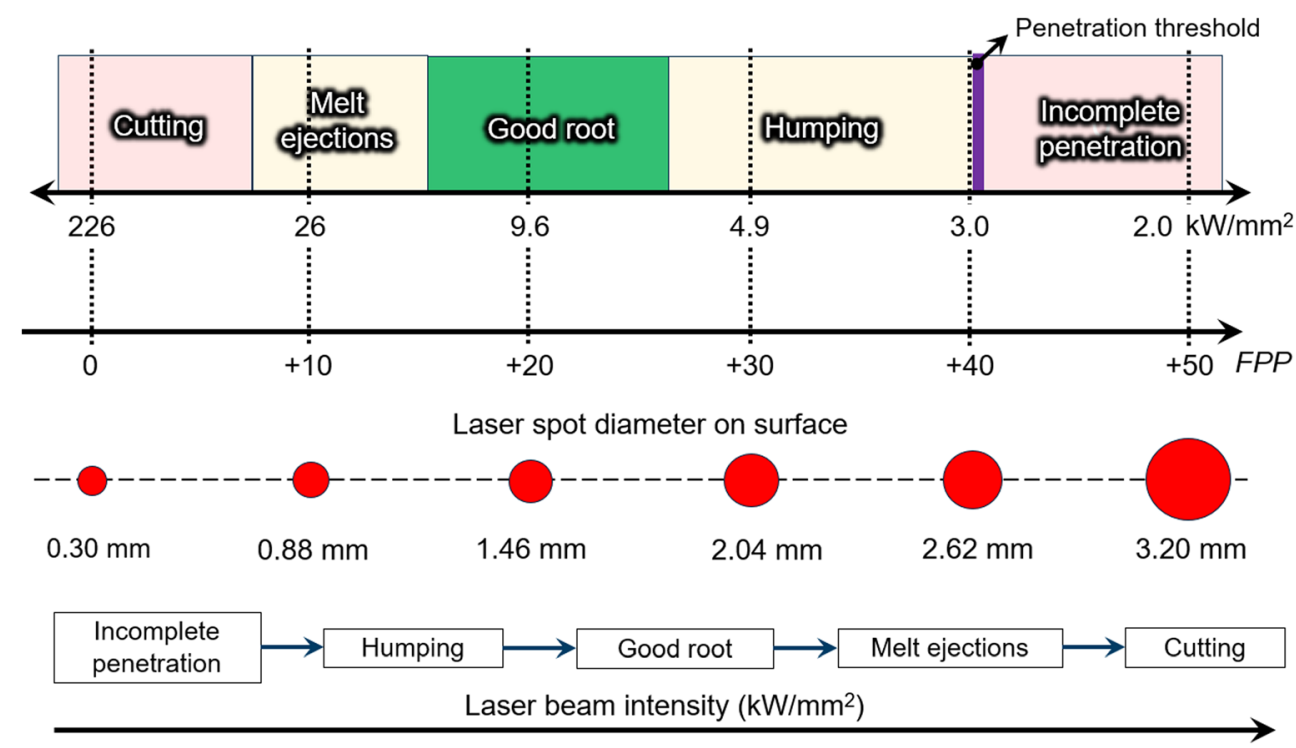

In the next experiments, $0.4 \mathrm{~mm}$ air gap between the plates was implemented to mitigate the humping issue by reducing the pressure at the keyhole exit. A leading arc is preferable for air gap setup since extra molten material is required to sustain the keyhole. Otherwise, most of the laser beam will go through the plates and no weld may be formed, especially at large $D_{L A}$. Application of parameters from Weld No. 3.1 (7 kW at $1.5 \mathrm{~m} / \mathrm{min}$ welding speed) with leading $\operatorname{arc}(8 \mathrm{~m} /$ min WFR) provided severe humping; see Fig. 12 (Weld No. 3.5). This clearly indicates a harmful effect of the arc added to laser beam within short $D_{L A}$. Further, the laser power was increased to $10 \mathrm{~kW}$ and full penetration was achieved but some humping generated; see Fig. 12 (Weld No. 3.7). Further, an increase in the laser power to $11 \mathrm{~kW}$ provided acceptable root quality (see Weld No. 3.8). Here, a slight increase of laser power was also positive for improved root quality as for autogenous LBW, which may be related to more favorable melt flows.

The next experimental runs were performed with $16 \mathrm{~kW}$ laser power with significantly defocused laser beam $(+42 \mathrm{~mm}$
$F P P)$ and zero air gap setup. Such large defocusing provides larger laser beam spot diameter (see Fig. 5). High laser power may provide lower hardness due to the wider fusion zone and slower cooling rates. Excessive humping was produced when using $1.0 \mathrm{~m} / \mathrm{min}$ travel speed, $15 \mathrm{~mm} D_{L A}$, and $4.0 \mathrm{~m} / \mathrm{min}$ WFR for trailing arc (see Fig. 13, Weld No. 3.9). In a slight reduction in WFR from 4 to $2 \mathrm{~m} / \mathrm{min}$, the humping was significantly reduced, Weld No. 3.10. However, the root quality was still not acceptable. Such behavior indicates that even very slight adjustment of the parameters can lead to different results and demonstrates that the LAHW process is highly sensitive. With an increase of welding speed from 1.0 to 1.2 $\mathrm{m} / \mathrm{min}$, humping was marginally mitigated; see Weld No. 3.11. A further increase of welding speed to $1.4 \mathrm{~m} / \mathrm{min}$ resulted in inconsistent root quality with variation in reinforcement height of weld seam; see Weld No. 3.12. At this point, it becomes clear that there is insufficient laser power density to form an acceptable root, as indicated in Fig. 5, and further increase of lase power was not possible. When considering the large width of the root, it is possible that humping occurs

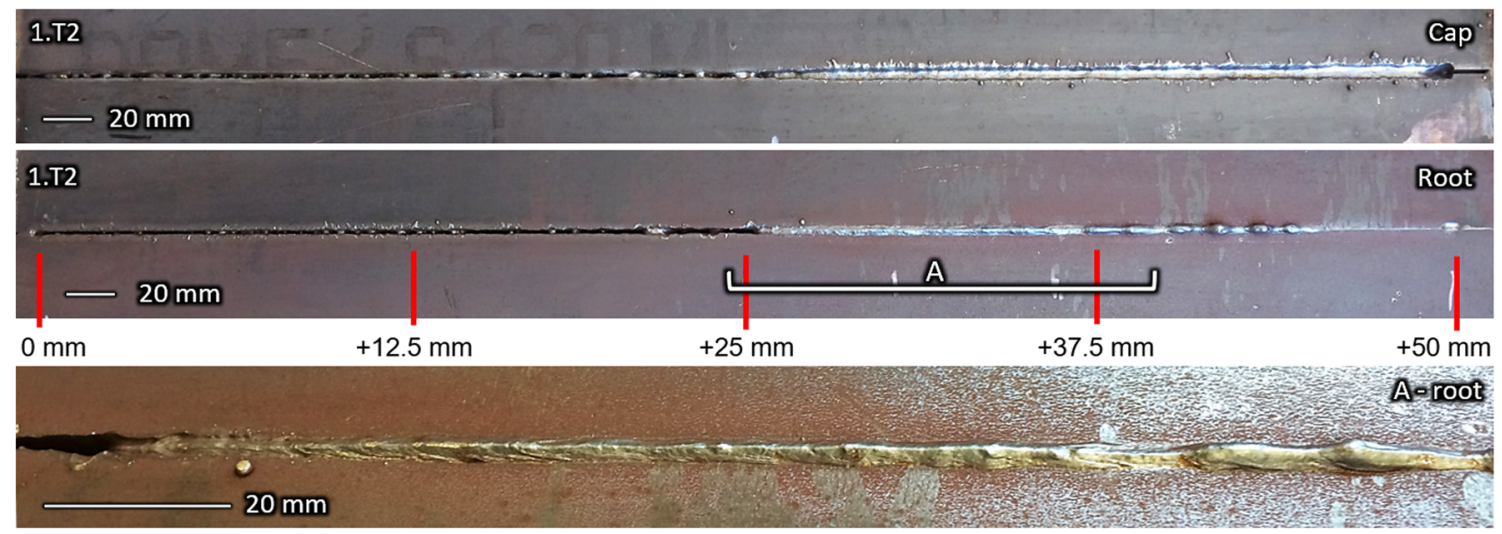

Fig. 6 Weld seam appearances of Weld No. $1 . \mathrm{T} 2$ with dynamic variation of focal point position. Constant parameters: $P_{L}=16 \mathrm{~kW}, v_{s}=1.5 \mathrm{~m} / \mathrm{min}$, and $0.0 \mathrm{~mm}$ air gap 
Fig. 7 Weld seam appearances of Welds No. 1.1-1.4. Constant parameters: $P_{L}=16 \mathrm{~kW}, v_{S}=1.5$ $\mathrm{m} / \mathrm{min}, 0.0 \mathrm{~mm}$ air gap, and $F P P$ $+30 \mathrm{~mm}$

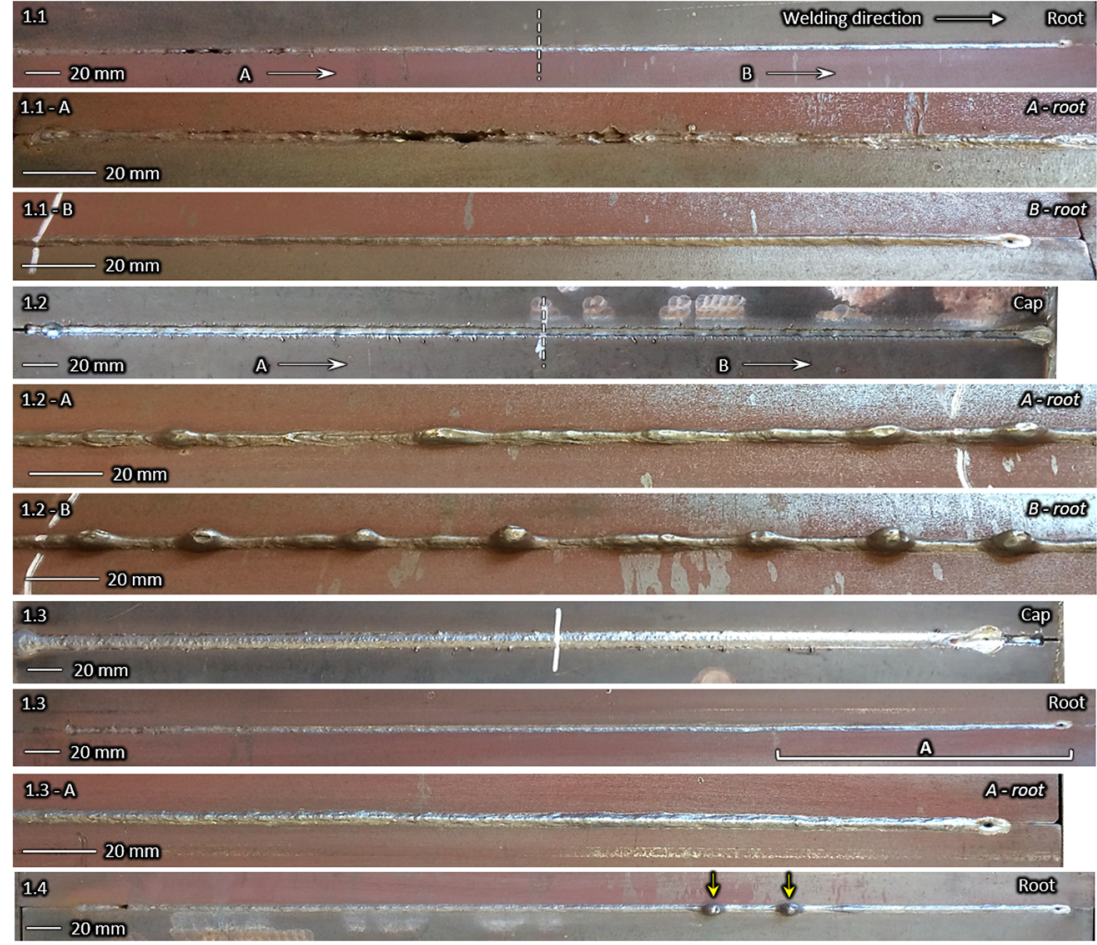

mainly due to the gravity force and low surface tension $[1,28$, 29].

\subsubsection{Welds with $10^{\circ}$ bevelling angle}

For initial experimental runs with decreased angle and $3 \mathrm{~mm}$ root face, $12 \mathrm{~kW}$ laser power at $1.5 \mathrm{~m} / \mathrm{min}$ welding speed was applied. Such high density of laser beam provided strong melt ejections; see Fig. 14 (Weld No. 4.1). The arc with low WFR marginally improved the quality of the root (Weld No. 4.2). Lower laser power of $10 \mathrm{~kW}$ (Weld No. 4.3) did not improve the root quality. The use of trailing arc caused weld pool instability which generated poor quality welds (Weld No. 4.4). A reduced laser-arc distance and a slight increase in $W F R$ (to $4 \mathrm{~m} / \mathrm{min}$ ) again provided insufficient quality of the root. This observation strongly supports the process physics phenomenon proposed in Fig. 5 and significant challenges to obtain high quality root for single-pass welding of $15 \mathrm{~mm}$ thick steel.

\subsection{Discussion on root quality}

Based on experimental results provided in subchapters 3.1 and 3.2 , the root quality in welding of $12 \mathrm{~mm}$ thick plates had higher quality with much wider process window compared to $15 \mathrm{~mm}$ thick plates. The bevelling angle had low influence showing high tolerance to preparations of the plates. For $12 \mathrm{~mm}$ thick plates, high root quality was achieved with $0.45 \mathrm{~kJ} / \mathrm{mm}$ laser heat input and $>15 \mathrm{~mm}$ laser-arc distance. The humping is decreasing with increase laser-arc distance

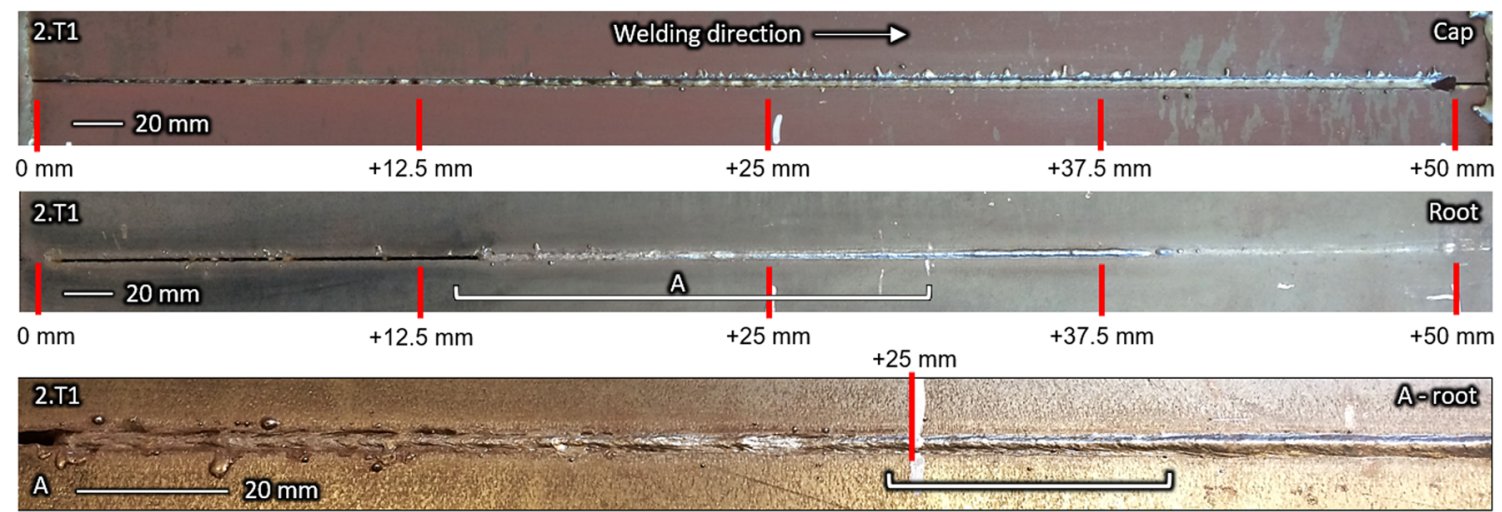

Fig. 8 Weld seam appearances of Weld No. 2.T1 with dynamic variation of focal point position. Constant parameters: $P_{L}=16 \mathrm{~kW}, v_{s}=1.5 \mathrm{~m} / \mathrm{min}$, and $0.0 \mathrm{~mm}$ air gap 


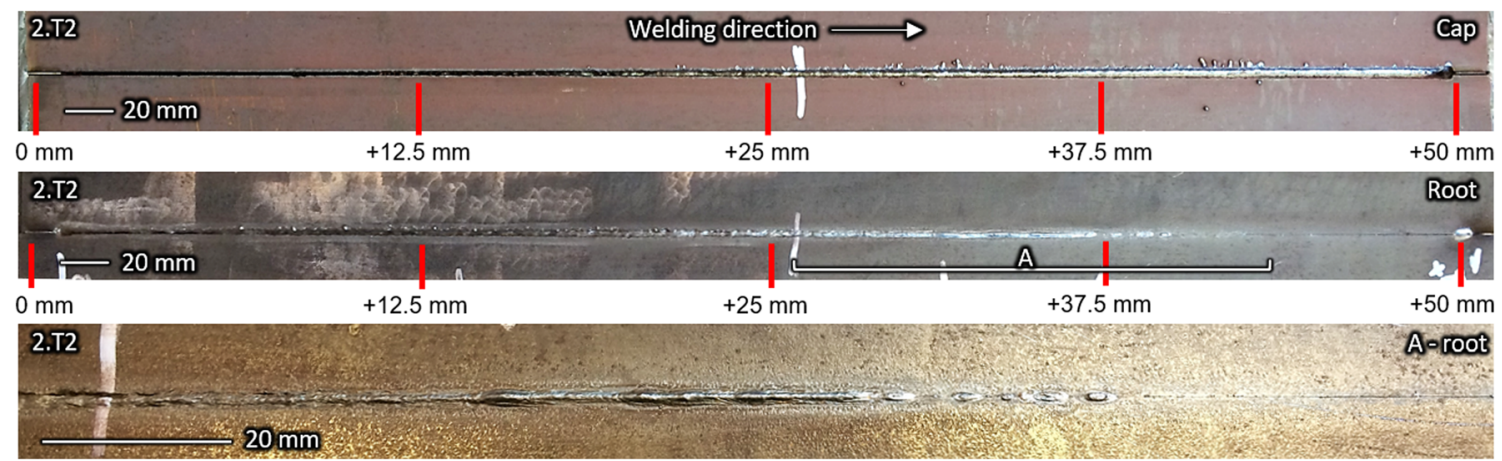

Fig. 9 Weld seam appearances of Weld No. 2.T2 with dynamic variation of focal point position. Constant parameters: $P_{L}=16 \mathrm{~kW}, v_{s}=2.0 \mathrm{~m} / \mathrm{min}$, and $0.4 \mathrm{~mm}$ air gap

which is related decrease of melt flows velocities [22] and lower negative interaction between the processes [30, 31]. Autogenous LBW provided better keyhole stability compared to LAHW; thus, higher quality of the root may be achieved. Optimized parameters for $12 \mathrm{~mm}$ thick plates showed high robustness and can be repeatable for long welds.

In case of $15 \mathrm{~mm}$ thick plates, a wide range of heat input in combination with different laser-arc distance, air gap, arc position, and FPP was tested. A leading arc with small air gap provided improved root quality with increased laser beam power. With defocused laser beam (positive $F P P$ ), too wide root width and too low beam intensity were observed, with an associated humping since it cannot shift towards melt ejection keyhole mode (see Fig. 5). The width of the root of the fusion zone had low importance, since Weld No. 3.9 had 2-3 times larger width than Weld No. 3.5 due to lower heat (from laser beam) input accordingly. It may be possible that melt flow dynamics, surface tension, and solidification conditions can be more important to redirect melt flows and counteract gravity forces to reduce melt dropout. The process physics of root formation conditions is presented in Fig. 15, including a comparison of the present study with published results. To the authors' knowledge, single-pass keyhole welding of $15 \mathrm{~mm}$ thick steel plates cannot be found among publications, especially related to root formation phenomena based on the weld length. Therefore, smaller thickness than $15 \mathrm{~mm}$ thick plate was selected for comparison. In fact, due to Y-bevelling, effective thickness of the plates supposed to be slightly reduced and may be compared to 11 to $12 \mathrm{~mm}$ thick plates. However, it is important to note that Y-bevelling is not the same as straight I-bevelling since the laser beam may be sensitive to surface conditions $[32,33]$. As main observation, after reaching the full penetration, humping or dropout occurred. A further increase in the laser beam power provides smooth root appearance with a slight reinforcement. Subsequent increase in laser power provides melt ejection mode generating underfill/ undercuts in the root area since portion of base metal is expulsed trough keyhole bottom. The present case with carbon steel and $15 \mathrm{~mm}$ thickness has a very narrow process window. This may be related to the thickness of the plates where high power is needed to penetrate the whole plate. High power laser is connected to faster downward melt flows at the keyhole front wall $[17,34]$ as molten humps having a complex topology [16, 35], higher temperatures [36], and more vigorous vapor plume oscillations and velocities [14, 37]. The latter case is very special. It is well known that the keyhole is more

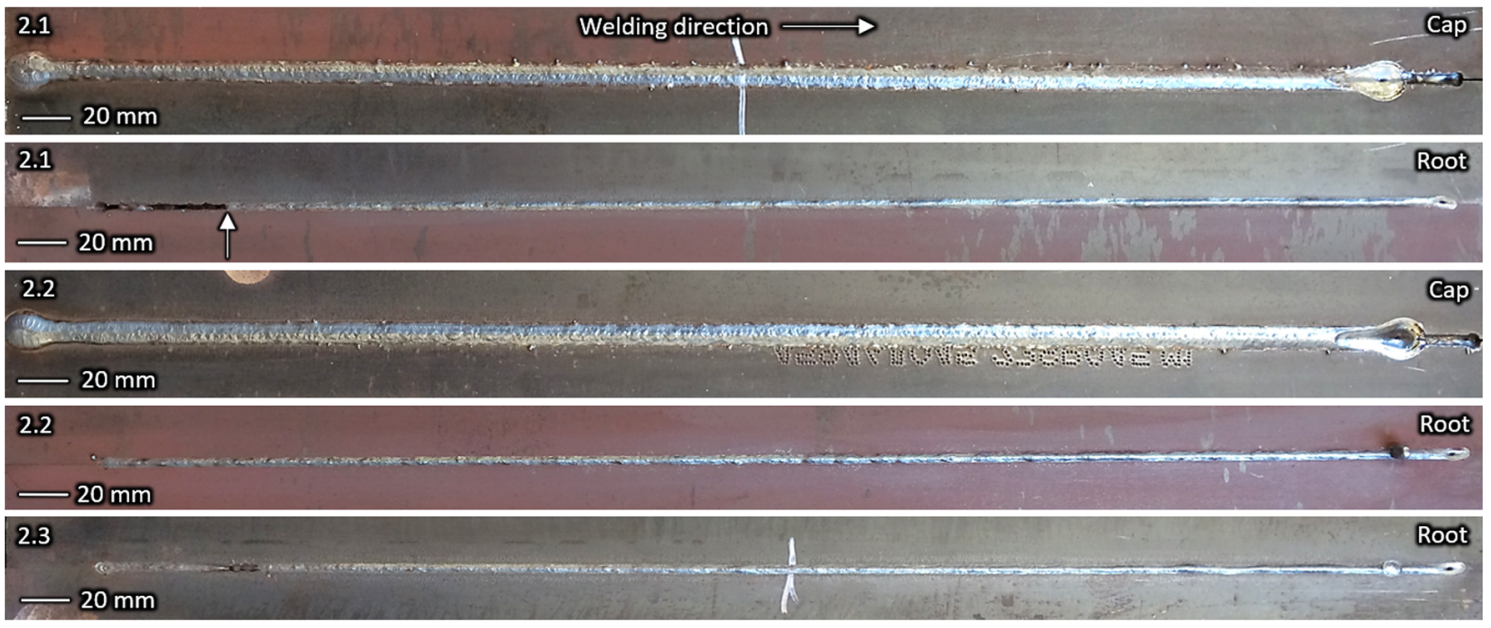

Fig. 10 Weld seam appearances of Weld No. 2.1-2.3. Constant parameters: $P_{L}=16 \mathrm{~kW}, v_{s}=2.0 \mathrm{~m} / \mathrm{min}, 0.0 \mathrm{~mm}$ air gap, and $F P P+30 \mathrm{~mm}$ 
Fig. 11 Appearances of Weld No. 3.2-3.4. Constant parameters: $F P P=0 \mathrm{~mm}$ and $0.0 \mathrm{~mm}$ air gap
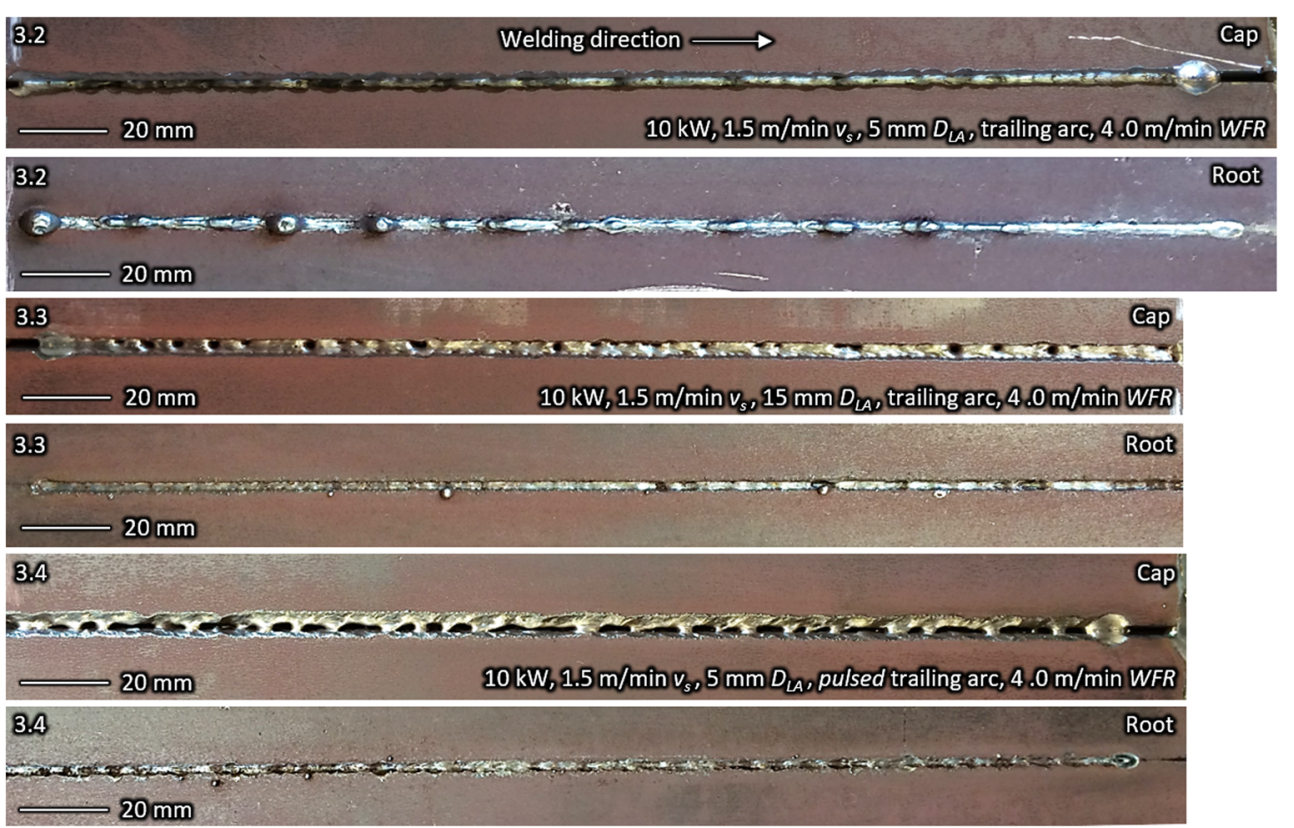

stable at lower power levels with lower density of the vapor plume, called as weakly ionized plasma [38]. At higher power levels, this ionized plasma is significantly more dense [39], resulting in lower penetration depth. Significantly lesser vapor plume is achieved at reduced ambient pressure conditions [40], resembling electron beam welding in vacuum. As a result, much higher penetration depth can be achieved with significantly improved keyhole stability [41]. Jiang et al. [42] obtained significantly wider process window at $0.1 \mathrm{kPa}$ pressure in single-pass welding of $10 \mathrm{~mm}$ thick high-strength steel. Reisgen et al. [3] showed that good root quality can be achieved even in welding of $50 \mathrm{~mm}$ thick steel plates with single-pass using only $16 \mathrm{~kW}$ disk laser power (in vacuum, pressure at $0.1 \mathrm{kPa}$ ) at $0.25 \mathrm{~m} / \mathrm{min}$ welding speed. Researchers from TRUMPF GmbH published results [43] showing a promising equipment with improved coaxial shielding during LBW providing smooth root quality, while conventional shielding conditions provided humping. In fact, such studies are very rarely published. Hence, the application of LBW/ LAHW under atmospheric conditions requires a proper selection of shielding gas and welding conditions. Moreover, based on results from Fig. 15, the chemical composition of the BM and shielding gas is important. The effect of filler wire should also be considered since it can influence on the physical properties of the molten metal during solidification with surface tension probably being the most influential during root formation $[6,29]$.

The optimization guidelines for LAHW can be developed and shown in Fig. 16. The dynamic variation in focal point position is an excellent method to find the balance between the laser beam intensity and the welding speed. Then the arc source may be added. However, further optimization of parameters, including arc source parameters, is required. A special attention is required for the air gap which must be constant

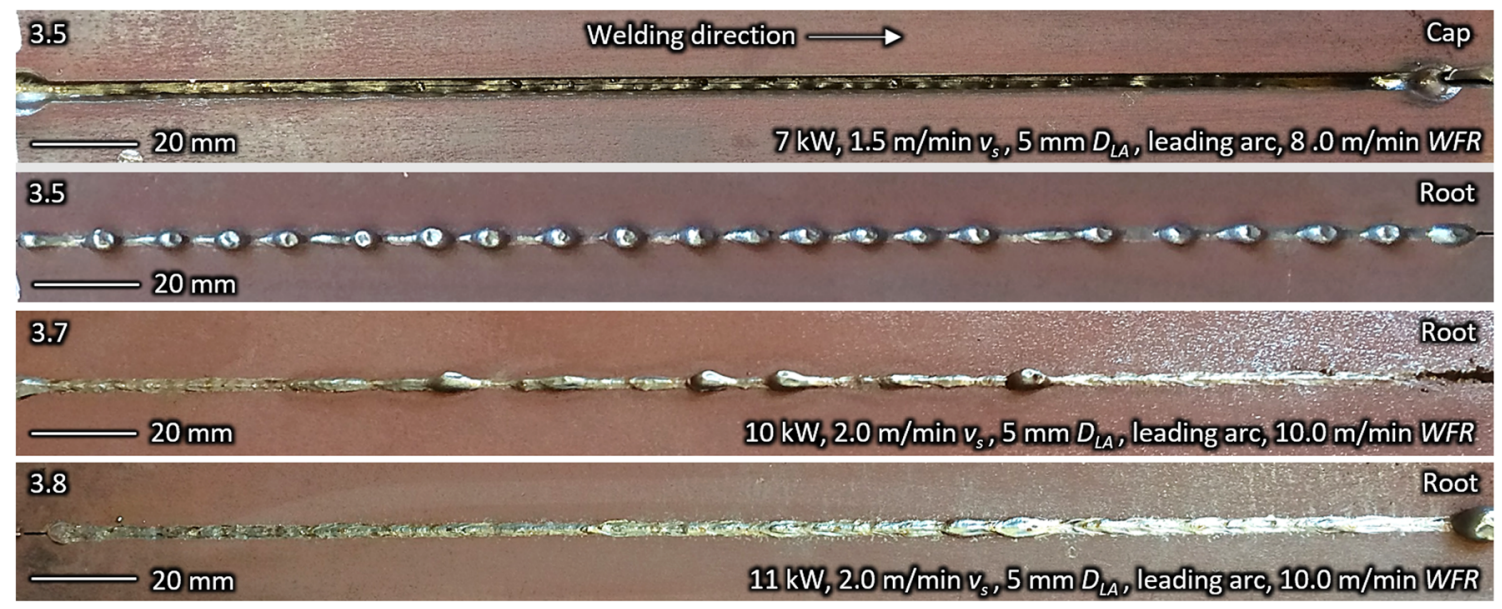

Fig. 12 Appearances of Weld No. 3.5, 3.7, and 3.8. Constant parameters: $F P P=0 \mathrm{~mm}$ and $0.4 \mathrm{~mm}$ air gap 
Fig. 13 Appearances of Weld No. 3.9-3.12. Constant parameters: $F P P=+42 \mathrm{~mm}$, $0.0 \mathrm{~mm}$ air gap and trailing arc position

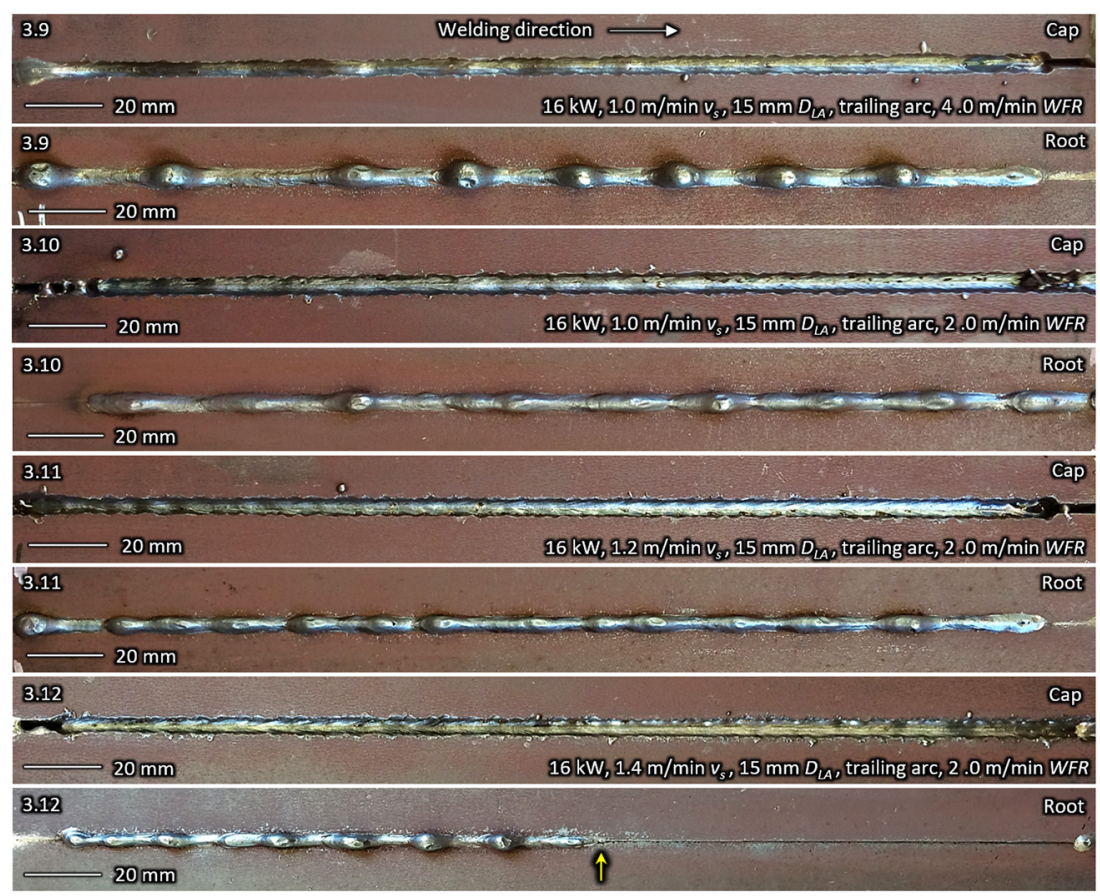

penetration if it is decreasing or sagging if it is increasing. Some guidelines are provided in literature [44-46]. If the LAHW with close proximity of heat sources fails, a tandem process should be used. The tandem process is viable option since filler from the arc may positively affect the root microstructure. There is a weak interaction between the laser beam
Fig. 14 Appearances of Weld No. 4.1-4.5. Constant parameters: $0 \mathrm{~mm} F P P$ and air gap $0.0 \mathrm{~mm}$

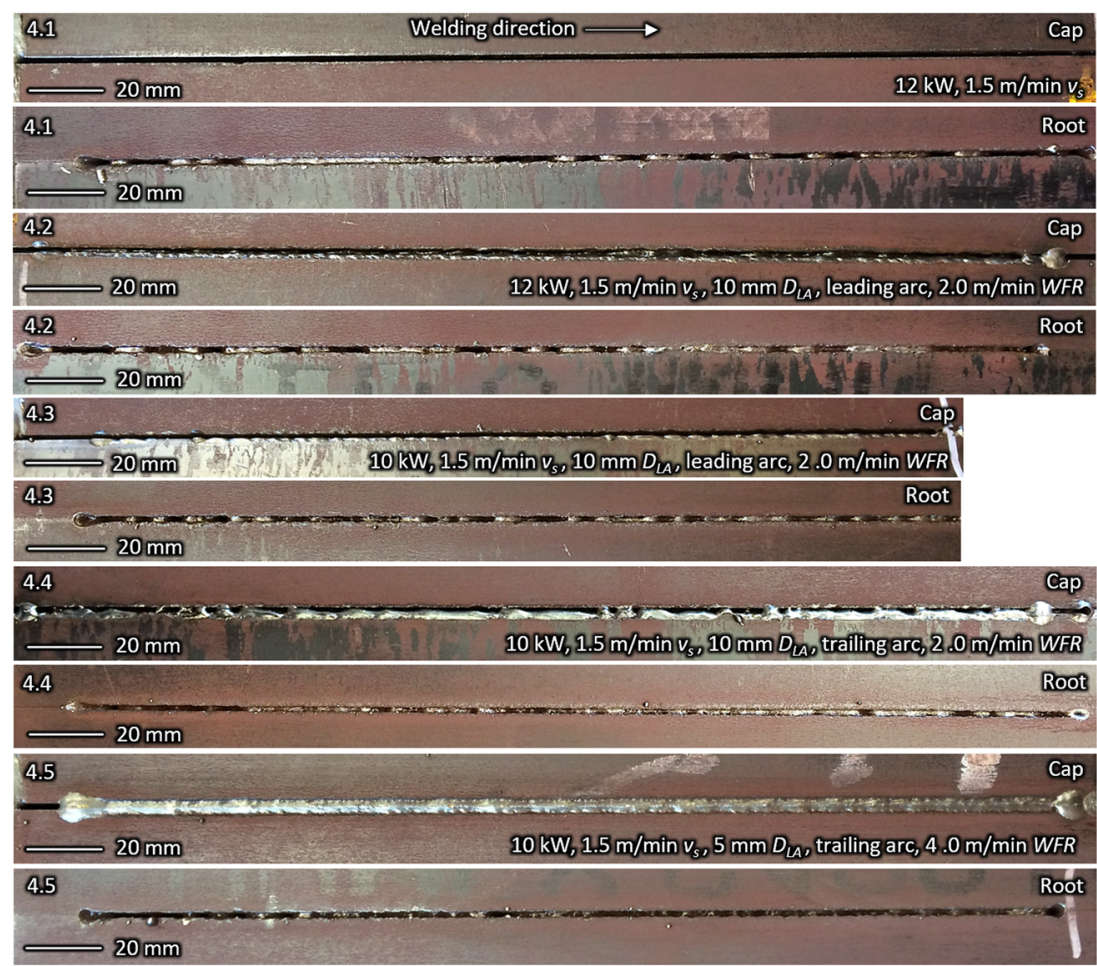


Fig. 15 Comparison of present study case a with published results from $\mathbf{b}, \mathbf{c}$ TRUMPF $\mathrm{GmbH}[5,27]$ and d, e Osaka University [18]. IP is incomplete penetration, $H$ is humping mode, $G R$ is bandwidth providing good (acceptable) root quality, and $M E$ is melt ejection mode. N/A means not reported. Red vertical lines mean approximate location of penetration threshold (a)
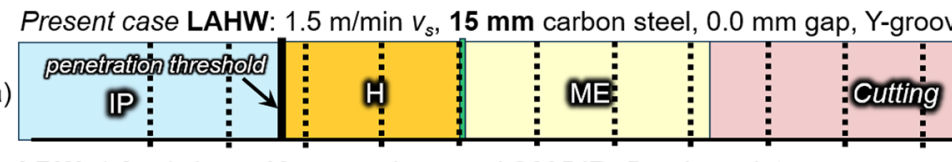

Beam diameter

LBW: $1.0 \mathrm{~m} / \mathrm{min} v_{s}, 12 \mathrm{~mm}$ carbon steel S235JR, Bead-on-plate

(b)

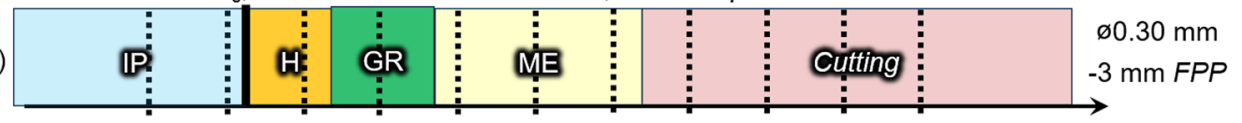

LBW: $1.0 \mathrm{~m} / \mathrm{min} \mathrm{v}_{s}, 12 \mathrm{~mm}$ duplex stainless steel 1.4462, Bead-on-plate

(c)

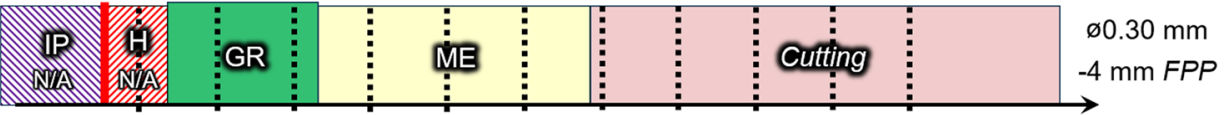

LAHW: $1.5 \mathrm{~m} / \mathrm{min} v_{s}, 11 \mathrm{~mm}$ carbon steel HT780, $\mathrm{Ar}+20 \% \mathrm{CO}_{2}, 0.5 \mathrm{~mm}$ gap, l-groove

(d)

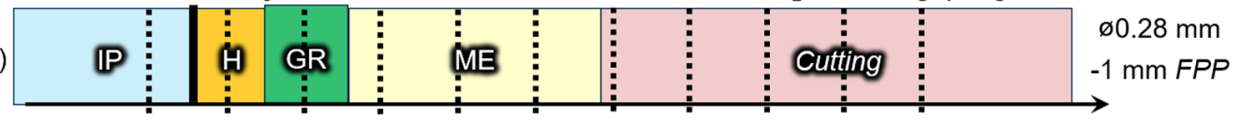

LAHW: $1.5 \mathrm{~m} / \mathrm{min} v_{s}, 11 \mathrm{~mm}$ carbon steel HT780, $100 \% \mathrm{CO}_{2}, 0.5 \mathrm{~mm}$ gap, l-groove

(e)
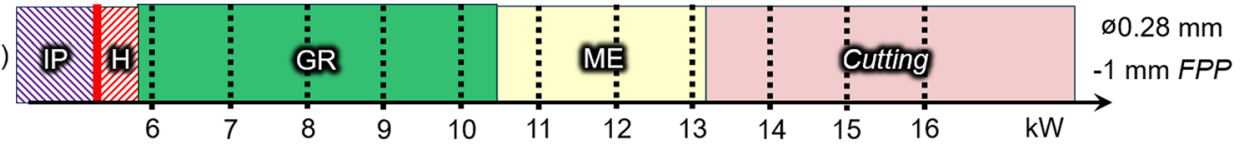

and the arc by employing a tandem process. At critically high welding speeds, an unstable arc may occur providing poor quality of welds [47].

\subsection{Microstructure and hardness}

Macrosections from good quality welds were selected to study the cross-section weld appearance, microstructure, hardness, and Charpy-V toughness (at $-50^{\circ} \mathrm{C}$ ). The macrosections are shown in Fig. 17. The welds had sound quality without porosity and cracking. Some porosity was observed for Weld No. 3.8 during filling pass with LAHW. This indicates that the arc welding parameters requires only minor further adjustments by increasing the current or increasing laser power (for filling pass) to have deeper penetration, and voltage for wider arc to melt edges properly to avoid porosity.

Hardness measurements, based on ISO 6507-1 [48], were performed for $12 \mathrm{~mm}$ thick plate with high heat input $\left(Q_{H}=\right.$ $0.91 \mathrm{~kJ} / \mathrm{mm}$ ) and for $15 \mathrm{~mm}$ thick plates with low heat input ( $Q_{H}=0.47 \mathrm{~kJ} / \mathrm{mm}$ for root). The results shown in Fig. 18 reveal that the hardness level in the arc part of the weld metal was very low ( $230 \mathrm{HV})$ which is only slightly higher than the $\mathrm{BM}$ which has $180 \mathrm{HV}$. The HAZ of the arc part has also low hardness of $\sim 260 \mathrm{HV}$. Moreover, the laser zone had also low hardness for both WM and HAZ (see Weld No. 2.1). This is positive for qualification of single-pass LAHW. The reason for low hardness even for the laser zone is that relatively high heat input was used $\left(Q_{H}=0.91 \mathrm{~kJ} / \mathrm{mm}\right)$ providing prolonged cooling rate. In the case of $15 \mathrm{~mm}$ thick plate (Weld No. 3.8), a

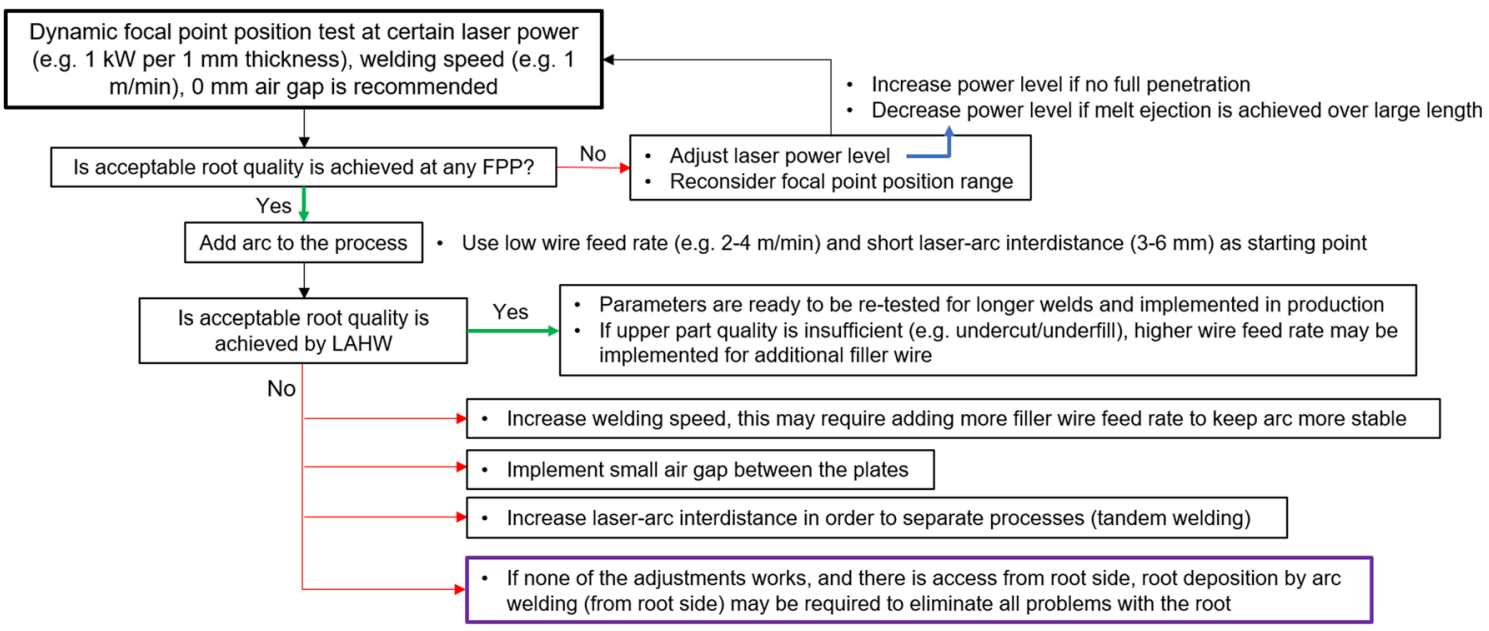

Fig. 16 Optimization strategy of process parameters for laser-arc hybrid welding 


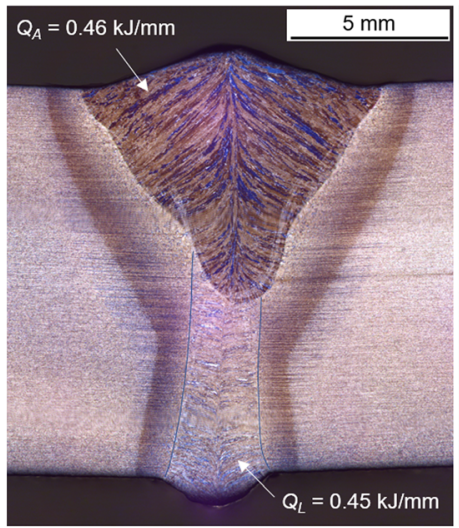

(a)

Weld No. 1.3

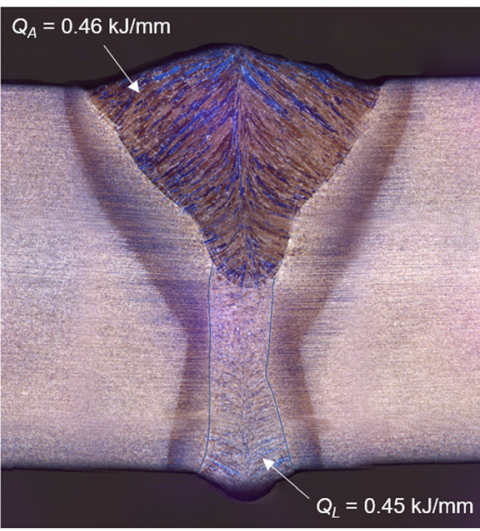

(b)
Weld No. 2.1

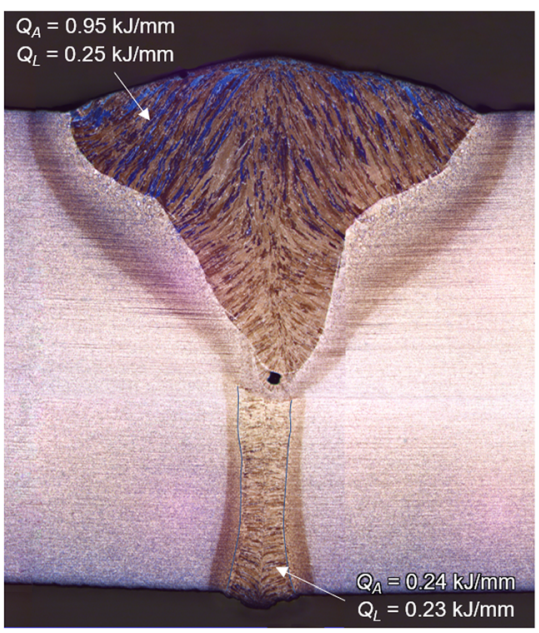

(c)

Weld No. 3.8

Fig. 17 Macrosections of selected welds: a $12 \mathrm{~mm}$ hick plate Weld No 1.3 with $20^{\circ}$ bevelling angle; b $12 \mathrm{~mm}$ thick plate Weld No. 2.1 with $10^{\circ}$ bevelling angle; and c $15 \mathrm{~mm}$ thick plate Weld No. 3.8

maximum hardness of $313 \mathrm{HV}$ (from individual ident) was measured in the HAZ close to the fusion line, while the average hardness was $307 \mathrm{HV}$. In WM, the hardness was low $(<$ $300 \mathrm{HV})$. The high maximum hardness here is in agreement with the low heat input employed $(0.47 \mathrm{~kJ} / \mathrm{mm})$. As a result, the filling pass provided tempering of the HAZ.

In the upper part of the welds with single-pass LAHW (e.g., Weld No. 2.1) or filler pass from the arc (e.g. Weld No. 3.8), a fine-grained acicular ferrite was developed regardless of welding parameters due to low dilution (high amount of added filler metal), as shown in Fig. 19. Weld No 2.1 had some coarse bainitic plates due to lower heat input and faster cooling rate.

In the laser part of the weld, favorable microstructure was developed with mixture of acicular ferrite and upper bainite with coarse platelets in WM in the case of $12 \mathrm{~mm}$ plate with single-pass LAHW (Weld No 2.1); see Fig. 20. For the $15 \mathrm{~mm}$ plate (Weld No. 3.8), more bainite with finer platelets was developed due to two times lower heat input than Weld No. 2.1 resulting in much faster cooling rates.

The microstructure in the coarse grain heat affected zone (CGHAZ) is shown in Fig. 21 with different magnifications. In the upper part (the arc zone), similar microstructure was developed regardless of welding parameters. However, larger prior austenite grains were formed with two-pass weld (Weld No. 3.8) due to high heat input from filling pass. The microstructure consisted mainly of upper bainite with some lath martensite. In the root area (laser zone), much larger prior austenite grain size was developed with predominantly upper bainite microstructure for higher heat input (Weld No. 2.1). The filling pass for Weld No. 3.8 had no effect on HAZ grain size in root area since most of heat was accumulated on the
Fig. 18 Hardness results of a $12 \mathrm{~mm}$ thick plate with high heat input (Weld No. 2.1) and b $15 \mathrm{~mm}$ thick plates with low heat input (Weld No. 3.8)

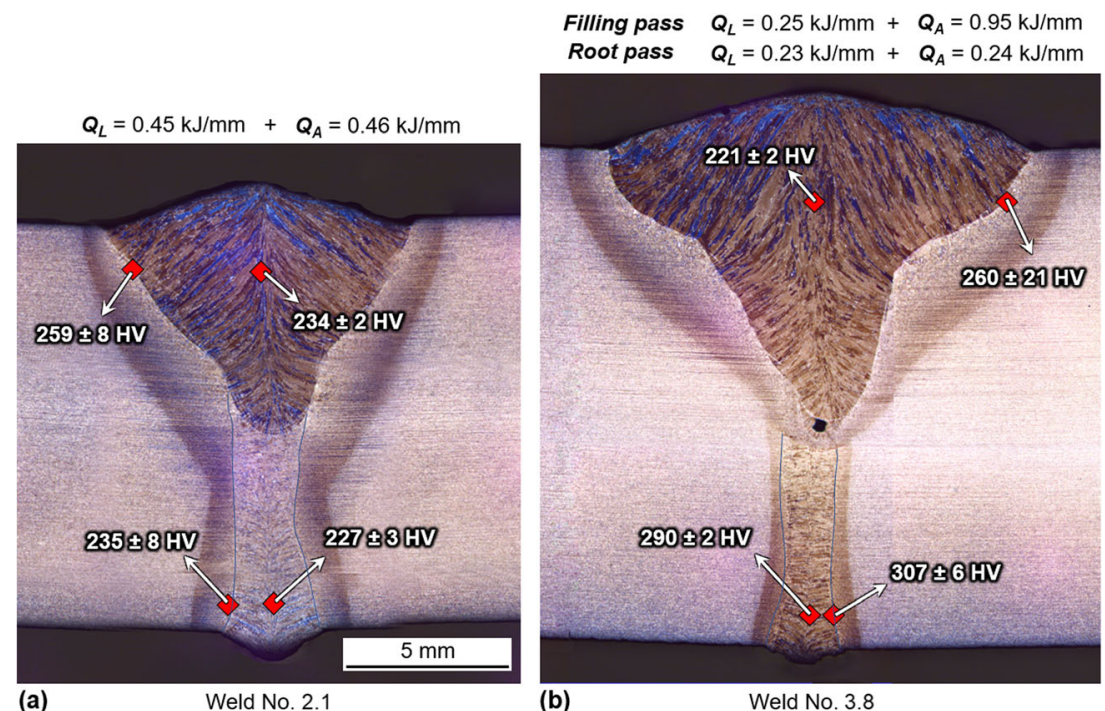




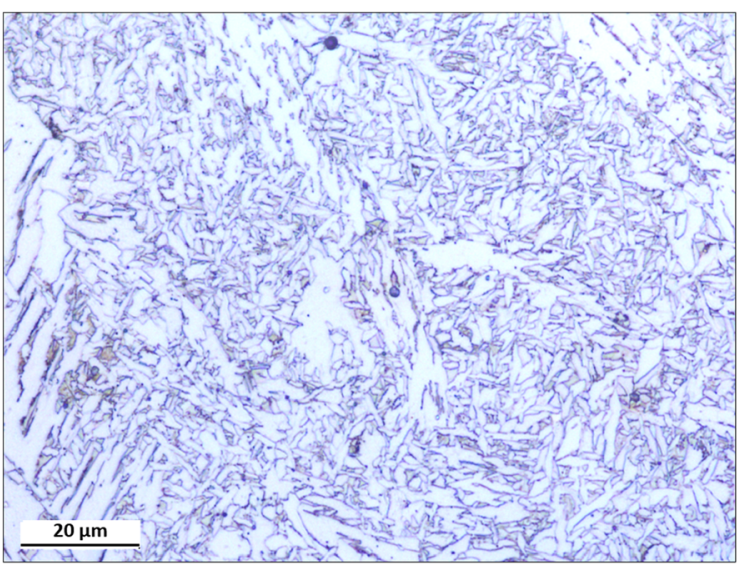

Weld No. 2.1

Single pass: $Q_{A}=0.45 \mathrm{~kJ} / \mathrm{mm} ; Q_{L}=0.46 \mathrm{~kJ} / \mathrm{mm}$

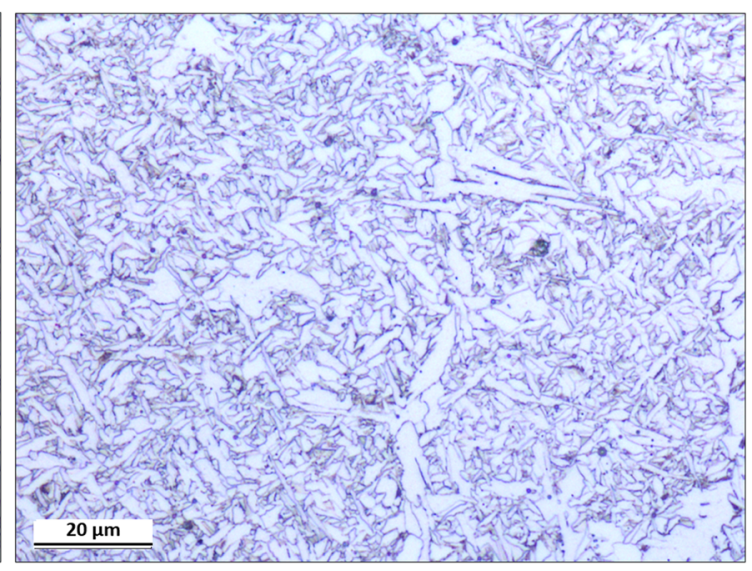

Weld No. 3.8

Filling pass: $Q_{A}=0.95 \mathrm{~kJ} / \mathrm{mm} ; Q_{L}=0.25 \mathrm{~kJ} / \mathrm{mm}$

Fig. 19 Microstructure evolution in weld metal of arc zone in case of $12 \mathrm{~mm}$ thick plates Weld No. 2.1 (on the left) and $15 \mathrm{~mm}$ thick plates Weld No. 3.8 (on the right)

top. For low heat input (Weld No. 3.8), the austenite grains were smaller containing more martensite due to faster cooling rates.

\subsection{Charpy V-notch toughness results}

The Charpy test results are shown in Fig. 22. Welds No. 1.3 and 2.1 provided similar toughness since the same heat input was applied. Both WM and FL provided higher toughness than the minimum acceptable $27 \mathrm{~J}$ at $-50^{\circ} \mathrm{C}$. The average toughness was slightly higher for FL than in WM. By inspection of macrophotos of Charpy specimens (see Fig. 23), the fracture did not deviate from FL/BM to adjacent areas in most of the cases. However, high toughness was obtained for FL providing $95 \mathrm{~J}$ due to fracture path deviation into the base metal (see Fig. 23). In the case of $15 \mathrm{~mm}$ thick plates, higher toughness was observed in WM. However, more unfavorable microstructure was developed in the laser zone (Weld No. 3.8) with higher amount of martensite (see Fig. 21) providing higher hardness (290 HV in WM and 310 in HAZ; see Fig. 18). It is important to note that the V-notch includes both the laser and arc zone (see Fig. 3); thus, the arc zone will also contribute to the total impact energy. Weld No. 3.8 had twopass welding with high heat input from filling pass $(1.20 \mathrm{~kJ} /$ $\mathrm{mm}$; see Table 4). Therefore, the root area was tempered due to the subsequent arc heat input (the martensite was subjected to some tempering). This possibly explains the higher toughness observed. Moreover, based on Fig. 20, smaller grains and platelets were produced providing higher toughness compared to single-pass weld (Weld No. 1.3 and 2.1). In addition, the arc zone microstructure for Weld No. 3.8 had much lower amount of coarse bainite (see Fig. 19), which also contributed to higher toughness. In case of FL, all welds regardless of heat inputs had similar toughness.

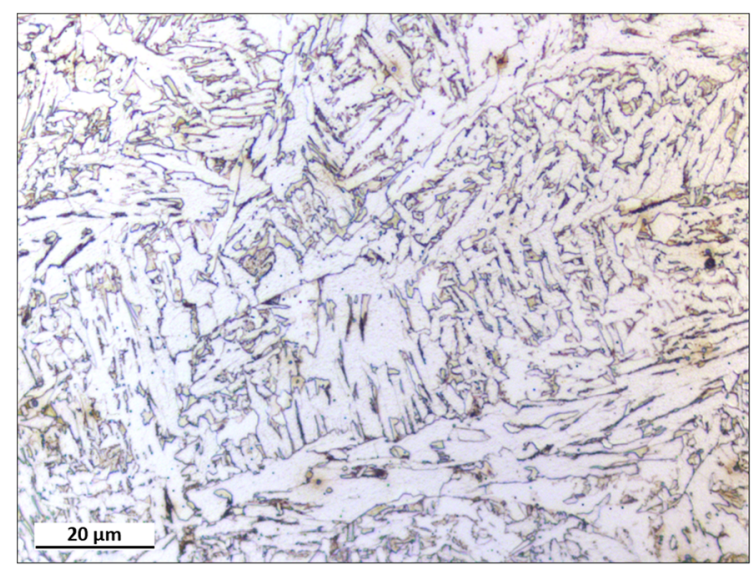

$\begin{aligned} & \text { Weld No. } 2.1 \\ & \text { Single pass: } Q_{A}=0.45 \mathrm{~kJ} / \mathrm{mm} ; Q_{L}=0.46 \mathrm{~kJ} / \mathrm{mm}\end{aligned}$

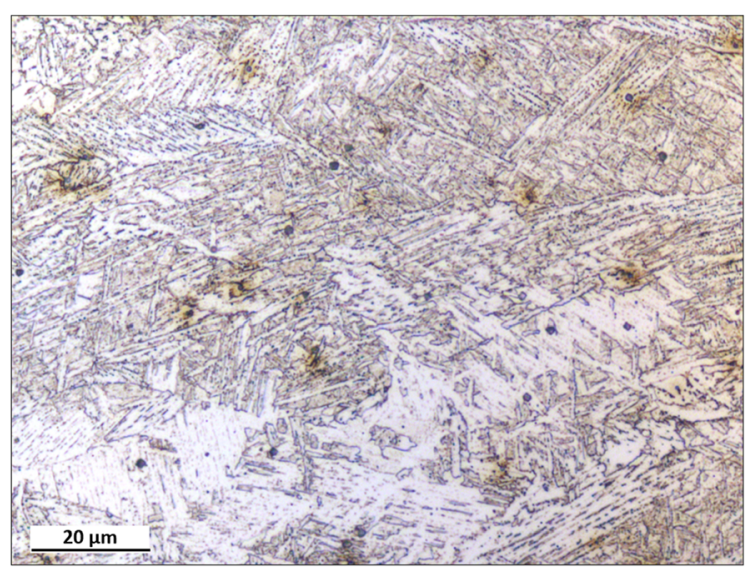

Weld No. 3.8

Root pass: $Q_{A}=0.24 \mathrm{~kJ} / \mathrm{mm} ; Q_{L}=0.23 \mathrm{~kJ} / \mathrm{mm}$

Fig. 20 Microstructure evolution in weld metal of laser zone of $12 \mathrm{~mm}$ thick Weld No. 2.1 (on the left) and $15 \mathrm{~mm}$ thick Weld No. 3.8 (on the right) 
Fig. 21 Microstructure evolution in CGHAZ near fusion line of $12 \mathrm{~mm}$ thick plate Weld No. 1.3 (on the left) and $15 \mathrm{~mm}$ thick plate Weld No. 3.8 (on the right)

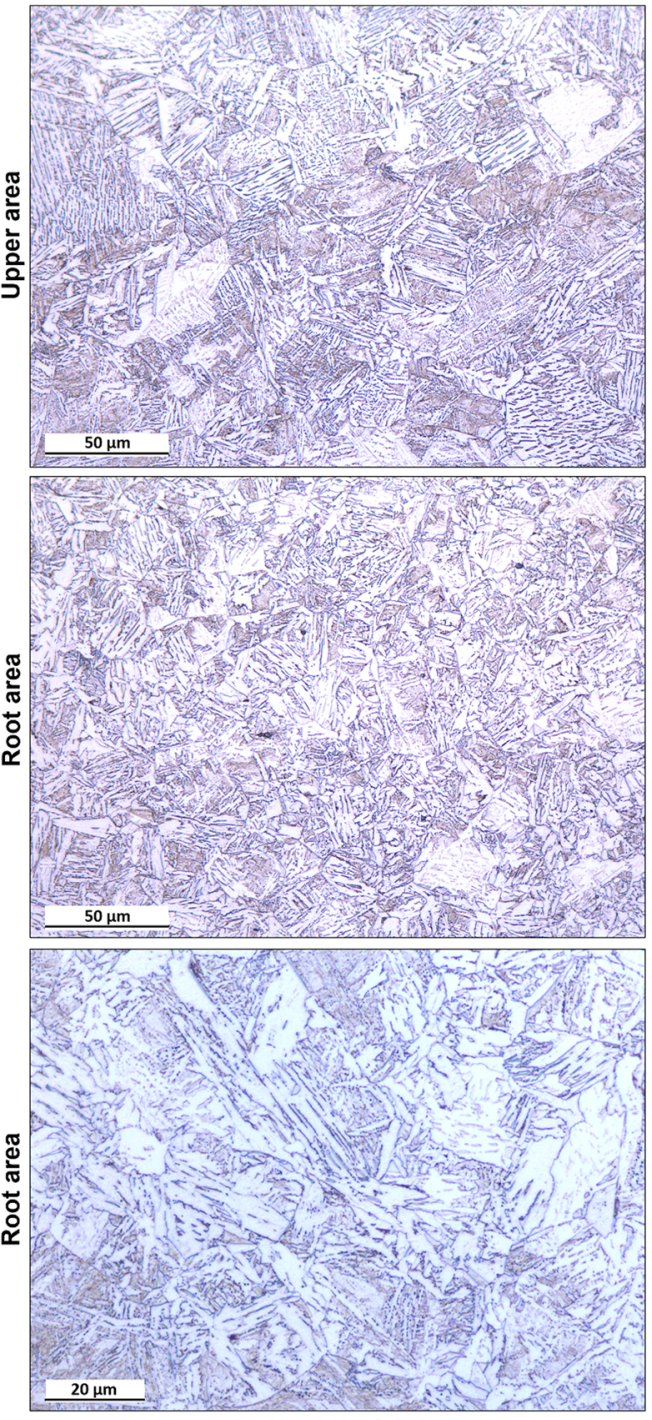

Weld No. 2.1

$Q_{A}=0.45 \mathrm{~kJ} / \mathrm{mm} ; Q_{L}=0.46 \mathrm{~kJ} / \mathrm{mm}$
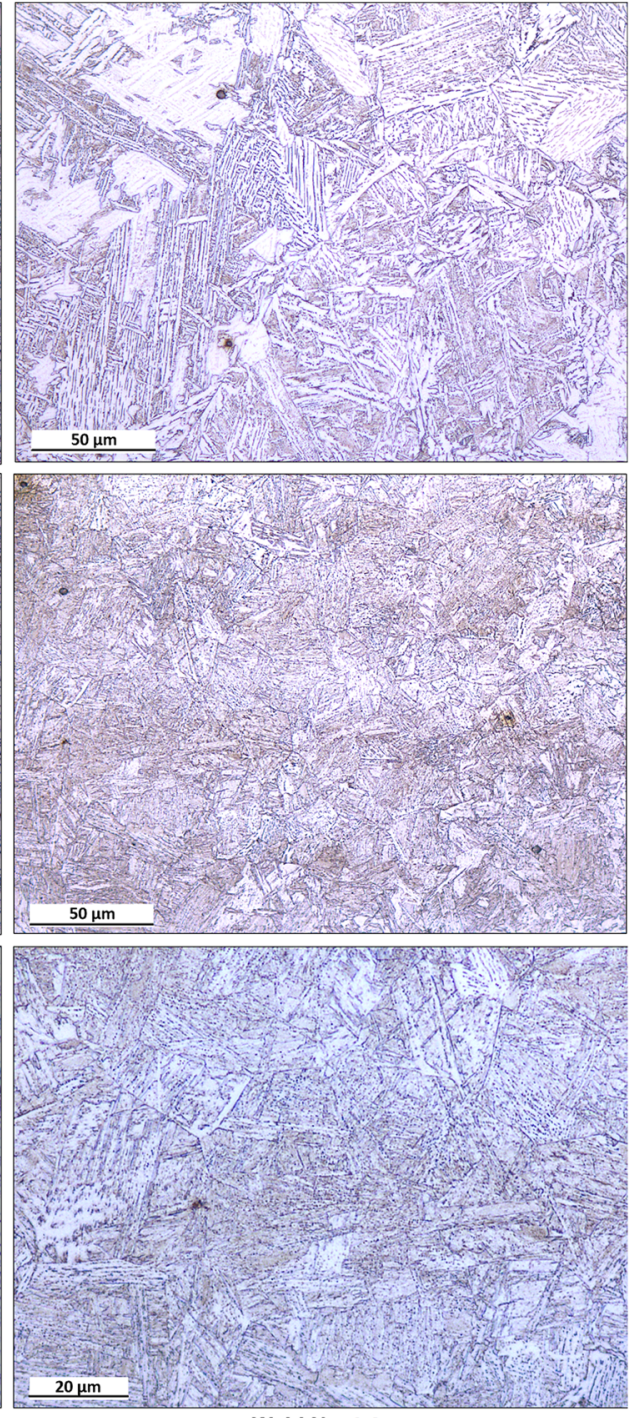

Weld No. 3.8

$Q_{A}=0.24 \mathrm{~kJ} / \mathrm{mm} ; Q_{L}=0.23 \mathrm{~kJ} / \mathrm{mm}$

Weld No. 1.3

Weld No. 2.1 Single-pass, $Q_{H}=0.91 \mathrm{~kJ} / \mathrm{mm}$ Single-pass, $Q_{H}=0.91 \mathrm{~kJ} / \mathrm{mm}$

Weld No. 3.8

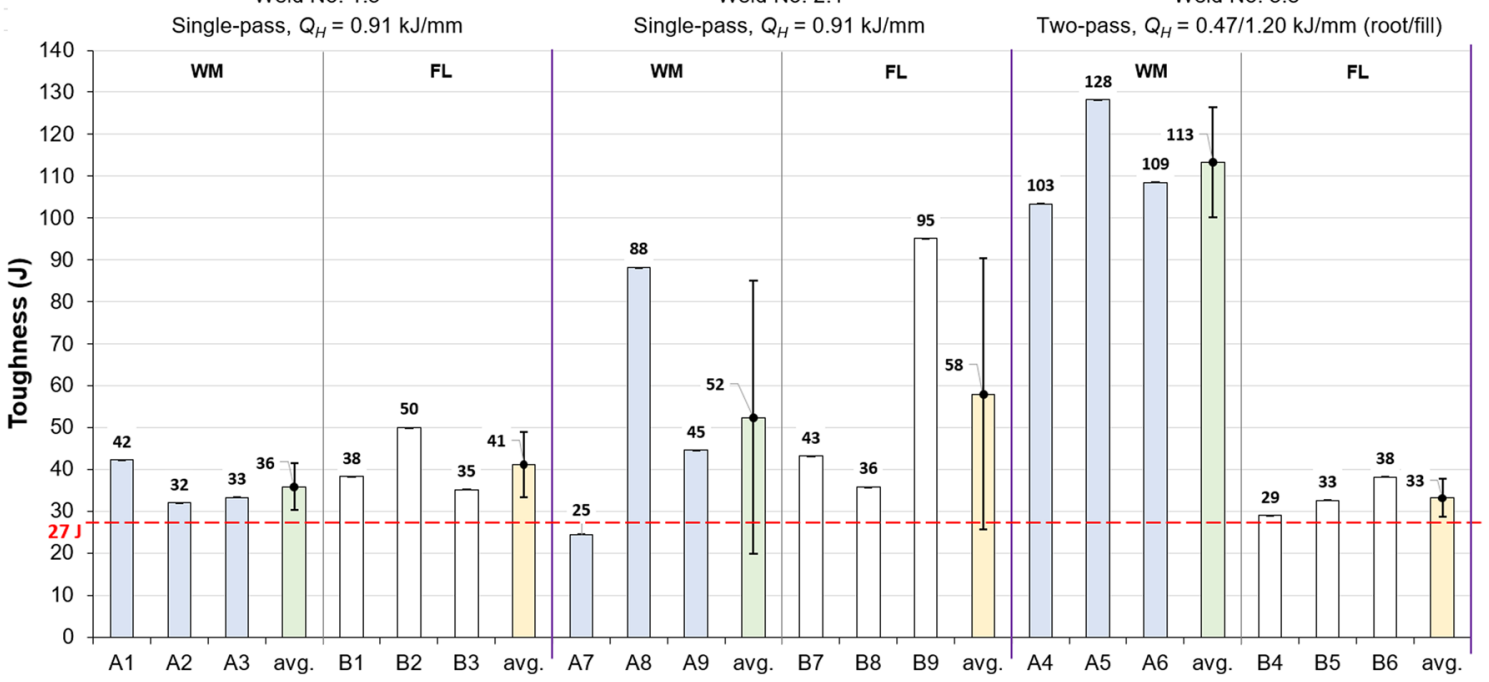

Fig. 22 Charpy V-notch toughness results of selected welds at $-50^{\circ} \mathrm{C}$ for $\mathrm{WM}$ and fusion line (FL) 

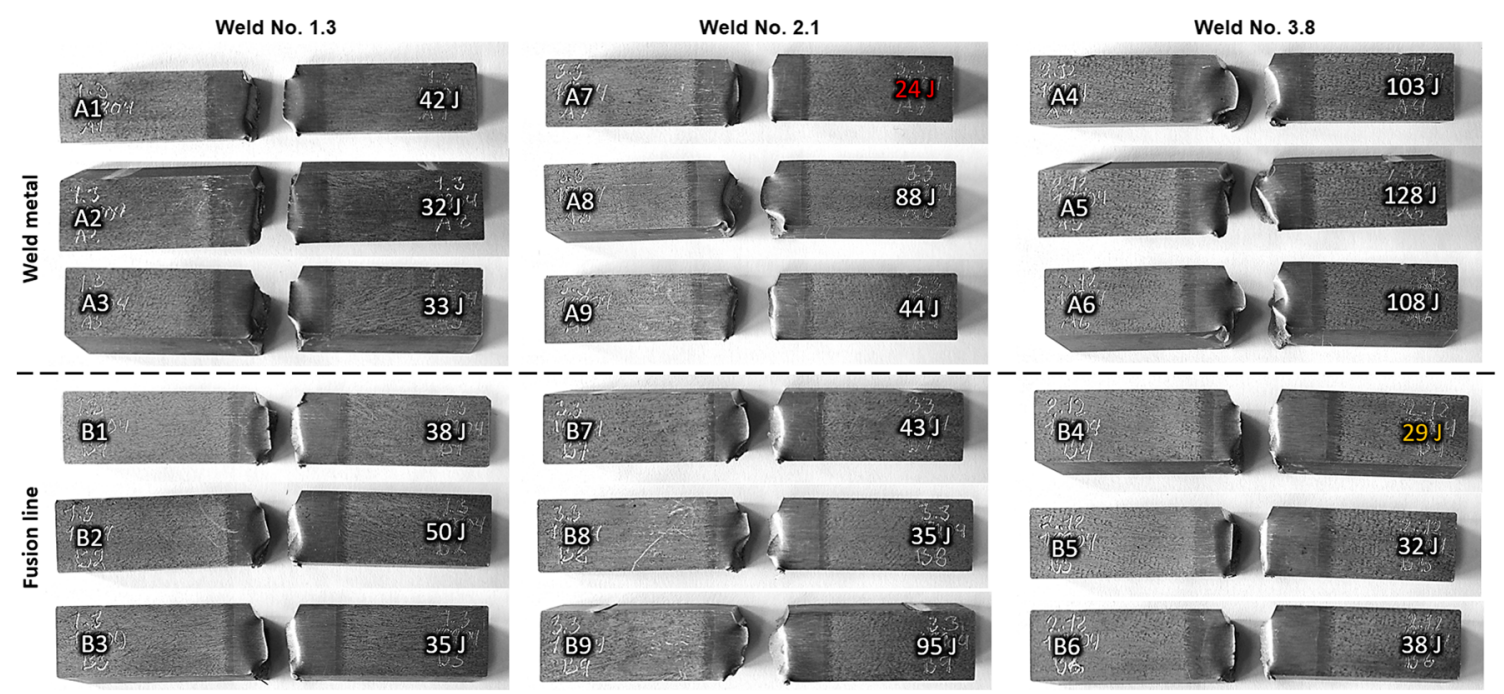

Fig. 23 Macrophotos of Charpy V-notch specimens after test

\section{Conclusions}

Based on the experimental work carried out the following conclusions can be drawn:

- Twelve millimeter thick plates were successfully welded with acceptable root quality with single-pass technique providing high production rates. Dynamic focal spot position testing is effective in finding suitable parameters, and optimal parameters are $0 \mathrm{~mm} F P P, 2 \mathrm{~m} /$ min welding speed, and 10-11 kW laser beam power.

- Fifteen millimeter thick plate welding with both autogenous LBW and LAHW was challenging with both bevelling geometries. Acceptable root quality was produced by using $11 \mathrm{~kW}$ laser beam power, $2.0 \mathrm{~m} / \mathrm{min}$ welding speed, $5 \mathrm{~mm}$ laser-arc interdistance, $0 \mathrm{~mm} F P P$, and using leading arc. Application of small air gap $(0.4 \mathrm{~mm})$ was beneficial to reduce humping.

- With increase of sheet thickness, more laser power is required to penetrate the plate. Therefore, there are higher temperatures and faster downward melt flows at keyhole front wall, which is responsible for unstable root formation, e.g., humping. In this case, surface tension forces are not sufficient to sustain the drop out during processing.

- Larger bevelling angles can reduce effective thickness; thus, lower laser power is needed to achieve full penetration with more stable welding conditions.

- Root formation modes are clearly defined. As soon as there is enough laser beam density to penetration a whole plate, the humping is formed. With further increase of laser power, the humping is changing to flatter root with acceptable quality regardless thickness of the plate used. Melt ejection mode develops with further increase of laser power resembling cutting process frequently forming underfills and undercuts in root.
- Two-pass welding for $15 \mathrm{~mm}$ thick plates provided high toughness in WM. This was attributed to tempering effect from filling pass with high heat input. However, it may provide higher distortions.

- Good toughness at $-50{ }^{\circ} \mathrm{C}$ with minimum of $27 \mathrm{~J}$ can be achieved in wide range of heat inputs $0.47-0.91 \mathrm{~kJ} / \mathrm{mm}$.

Acknowledgements The authors wish to acknowledge Statens vegvesen AS (Norway) for funding the project. FORCE Technology (Odense, Denmark) and SSAB Europe Oy (Raahe, Finland) are appreciated for the cooperation.

Author contribution Ivan Bunaziv: conceptualization, methodology, experimental work, investigation, and writing original draft. Cato Dørum: resources and advisory. Steen Erik Nielsen: advisory and experimental work. Pasi Suikkanen: resources. Xiaobo Ren, Bard Nyhus, and Magnus Eriksson: review and advisory. Odd M. Akselsen: review, editing, and supervision.

Funding Open access funding provided by SINTEF AS. The publication is based on the project in collaboration of SINTEF AS (Norway) with Statens vegvesen AS (Norway) as client.

Data availability The authors confirm that the data supporting the findings of this study are available within the article. Derived data supporting the findings of this study are available from the corresponding author on request.

\section{Declarations}

Ethical approval All authors confirm that they follow all ethical guidelines.

Consent to participate The authors declare that they consent to participate this paper.

Consent to publish The authors declare that they consent to publish this paper and agrees with the publication. 
Conflicts of interest The authors declare no competing interest.

Open Access This article is licensed under a Creative Commons Attribution 4.0 International License, which permits use, sharing, adaptation, distribution and reproduction in any medium or format, as long as you give appropriate credit to the original author(s) and the source, provide a link to the Creative Commons licence, and indicate if changes were made. The images or other third party material in this article are included in the article's Creative Commons licence, unless indicated otherwise in a credit line to the material. If material is not included in the article's Creative Commons licence and your intended use is not permitted by statutory regulation or exceeds the permitted use, you will need to obtain permission directly from the copyright holder. To view a copy of this licence, visit http://creativecommons.org/licenses/by/4.0/.

\section{References}

1. Webster S, Kristensen JK, Petring D (2008) Joining of thick section steels using hybrid laser welding. Ironmak Steelmak 35(7):496504. https://doi.org/10.1179/174328108X358505

2. Bunaziv I, Akselsen OM, Frostevarg J, Kaplan AFH (2018) Deep penetration fiber laser-arc hybrid welding of thick HSLA steel. J Mater Process Technol 256:216-228. https://doi.org/10.1016/j. jmatprotec.2018.02.026

3. Reisgen U, Olschok S, Jakobs S, Turner C (2016) Laser beam welding under vacuum of high grade materials. WELD WORLD 60(3):403-413. https://doi.org/10.1007/s40194-016-0302-3

4. Sokolov M, Salminen A, Kuznetsov M, Tsibulskiy I (2011) Laser welding and weld hardness analysis of thick section S355 structural steel. Mater Des 32(10):5127-5131. https://doi.org/10.1016/j. matdes.2011.05.053

5. Haug P, Rominger V, Speker N, Weber R, Graf T, Weigl M, Schmidt M (2013) Influence of laser wavelength on melt bath dynamics and resulting seam quality at welding of thick plates. Phys Procedia 41:49-58. https://doi.org/10.1016/j.phpro.2013.03.051

6. Frostevarg J (2018) Factors affecting weld root morphology in laser keyhole welding. Opt Lasers Eng 101(Supplement C):89-98. https://doi.org/10.1016/j.optlaseng.2017.10.005

7. Ilar T, Eriksson I, Powell J, Kaplan A (2012) Root humping in laser welding - an investigation based on high speed imaging. Phys Procedia 39:27-32. https://doi.org/10.1016/j.phpro.2012.10.010

8. Gebhardt MO, Gumenyuk A, Rethmeier M (2013) Solidification cracking in laser GMA hybrid welding of thick-walled parts. Science and Technology of Welding and Joining 19(3):209-213. https://doi.org/10.1179/1362171813Y.0000000171

9. Bunaziv I, Frostevarg J, Akselsen OM, Kaplan AFH (2018) The penetration efficiency of thick plate laser-arc hybrid welding. Int $\mathrm{J}$ Adv Manuf Technol 97(5):2907-2919. https://doi.org/10.1007/ s00170-018-2103-x

10. Turichin G, Kuznetsov M, Pozdnyakov A, Gook S, Gumenyuk A, Rethmeier M (2018) Influence of heat input and preheating on the cooling rate, microstructure and mechanical properties at the hybrid laser-arc welding of API 5L X80 steel. Procedia CIRP 74:748-751. https://doi.org/10.1016/j.procir.2018.08.018

11. Bunaziv I, Akselsen OM, Frostevarg J, Kaplan AFH (2019) Application of laser-arc hybrid welding of steel for lowtemperature service. Int J Adv Manuf Technol 102(5):2601-2613. https://doi.org/10.1007/s00170-019-03304-1

12. Pang S, Shao X, Li W, Chen X, Gong S (2016) Dynamic characteristics and mechanisms of compressible metallic vapor plume behaviors in transient keyhole during deep penetration fiber laser welding. Applied Physics A 122(7):702. https://doi.org/10.1007/ s00339-016-0230-5
13. Pang S, Chen X, Li W, Shao X, Gong S (2016) Efficient multiple time scale method for modeling compressible vapor plume dynamics inside transient keyhole during fiber laser welding. Opt Laser Technol 77:203-214. https://doi.org/10.1016/j.optlastec.2015.09. 024

14. Chen X, Pang S, Shao X, Wang C, Zhang X, Jiang P, Xiao J (2017) Sub-microsecond vapor plume dynamics under different keyhole penetration regimes in deep penetration laser welding. Journal of Physics D: Applied Physics 50(20):205601. https://doi.org/10. 1088/1361-6463/aa69b7

15. Zhang LJ, Zhang JX, Gumenyuk A, Rethmeier M, Na SJ (2014) Numerical simulation of full penetration laser welding of thick steel plate with high power high brightness laser. J Mater Process Technol 214(8):1710-1720. https://doi.org/10.1016/j.jmatprotec. 2014.03.016

16. Kaplan AFH, Matti RS (2015) Absorption peaks depending on topology of the keyhole front and wavelength. J Laser Appl 27(S2):S29012. https://doi.org/10.2351/1.4906469

17. Eriksson I, Powell J, Kaplan AFH (2013) Melt behavior on the keyhole front during high speed laser welding. Opt Lasers Eng 51(6):735-740. https://doi.org/10.1016/j.optlaseng.2013.01.008

18. Pan Q, Mizutani M, Kawahito Y, Katayama S (2016) Effect of shielding gas on laser-MAG arc hybrid welding results of thick high-tensile-strength steel plates. WELD WORLD 60(4):653664. https://doi.org/10.1007/s40194-016-0333-9

19. Zhang M, Zhang Y, Mao C, Hu Y, Chen G, Bi Z (2019) Experiments on formation mechanism of root humping in highpower laser autogenous welding of thick plates with stainless steels. Opt Laser Technol 111:11-19. https://doi.org/10.1016/j.optlastec. 2018.09.029

20. Zhang M, Liu T, Hu R, Mu Z, Chen S, Chen G (2020) Understanding root humping in high-power laser welding of stainless steels: a combination approach. Int J Adv Manuf Technol 106(11):5353-5364. https://doi.org/10.1007/s00170-020-05021-6

21. Tang G, Zhao X, Li R, Liang Y, Jiang Y, Chen H (2020) The effect of arc position on laser-arc hybrid welding of 12-mm-thick high strength bainitic steel. Opt Laser Technol 121:105780. https://doi. org/10.1016/j.optlastec.2019.105780

22. Bunaziv I, Dørum C, Nielsen SE, Suikkanen P, Ren X, Nyhus B, Eriksson M, Akselsen OM (2020) Laser-arc hybrid welding of 12and 15-mm thick structural steel. Int J Adv Manuf Technol 107(5): 2649-2669. https://doi.org/10.1007/s00170-020-05192-2

23. ISO 14341 - Welding consumables - Wire electrodes and weld deposits for gas shielded metal arc welding of non alloy and fine grain steels - Classification (2010). International Organization for Standardization

24. ISO 9016 - Destructive tests on welds in metallic materials - impact tests - test specimen location, notch orientation and examination (2012). International Organization for Standardization

25. ISO 17639 - Destructive tests on welds in metallic materials - macroscopic and microscopic examination of welds (2003). International Organization for Standardization,

26. ISO 22826 - Destructive tests on welds in metallic materials - hardness testing of narrow joints welded by laser and electron beam (Vickers and Knoop hardness tests) (2005). International Organization for Standardization,

27. Romminger V, Haug P, Speker N, Holzer M (2013) High-power full penetration welding behavior. 10 (3):36-40. doi:https://doi.org/ 10.1002/latj.201390036

28. Kristensen JK, Webster S, Petring D (2009) Hybrid laser welding of thick section steels - the HYBLAS project. Paper presented at the NOLAMP 12, Copenhagen, Denmark,

29. Petring D, Fuhrmann C, Wolf N, Poprawe R Progress in laserMAG hybrid welding of high-strength steels up to $30 \mathrm{~mm}$ thickness. In: 26th International Congress on Applications of Lasers and 
Electro-Optics (ICALEO), Orlando, Florida, USA, October 29th to November 1st 2007. Laser Institute of America, pp 300-307

30. Kutsuna M, Chen L Interaction of both plasmas in CO2 laser-MAG hybrid welding of carbon steel. In: LAMP 2002: International Congress on Laser Advanced Materials Processing, 2003. SPIE, pp 341-346

31. Fellman A, Salminen A Study of the phenomena of fiber laserMAG hybrid welding. In: 26th International Congress on Applications of Lasers and Electro-Optics (ICALEO), Orlando, Florida, USA, October 29th to November 1st 2007. Laser Institute of America, pp 871-880

32. Sokolov M, Salminen A, Somonov V, Kaplan AFH (2012) Laser welding of structural steels: influence of the edge roughness level. Opt Laser Technol 44(7):2064-2071. https://doi.org/10.1016/j. optlastec.2012.03.025

33. Wang H, Kawahito Y, Yoshida R, Nakashima Y, Shiokawa K (2018) A model to calculate the laser absorption property of actual surface. International Journal of Heat and Mass Transfer 118:562 569. https://doi.org/10.1016/j.ijheatmasstransfer.2017.11.023

34. Eriksson I, Powell J, Kaplan AFH (2011) Measurements of fluid flow on keyhole front during laser welding. Science and Technology of Welding and Joining 16(7):636-641. https://oi. org/10.1179/1362171811Y.0000000050

35. Matti RS, Kaplan AFH (2015) Analyzing and post-modelling the high speed images of a wavy laser induced boiling front. Phys Procedia 78:192-201. https://doi.org/10.1016/j.phpro.2015.11.043

36. Semak V, Matsunawa A (1997) The role of recoil pressure in energy balance during laser materials processing. Journal of Physics D: Applied Physics 30(18):2541-2552. https://doi.org/10.1088/ 0022-3727/30/18/008

37. Tenner F, Brock C, Gürtler F-J, Klämpfl F, Schmidt M (2014) Experimental and numerical analysis of gas dynamics in the keyhole during laser metal welding. Phys Procedia 56:1268-1276. https://doi.org/10.1016/j.phpro.2014.08.050

38. Katayama S, Kawahito Y, Mizutani M (2010) Elucidation of laser welding phenomena and factors affecting weld penetration and welding defects. Phys Procedia 5(Part B):9-17. https://doi.org/10. 1016/j.phpro.2010.08.024
39. Zou J, Yang W, Wu S, He Y, Xiao R (2016) Effect of plume on weld penetration during high-power fiber laser welding. J Laser Appl 28(2):022003. https://doi.org/10.2351/1.4940148

40. Katayama S, Yohei A, Mizutani M, Kawahito Y (2011) Development of deep penetration welding technology with high brightness laser under vacuum. Phys Procedia 12(Part A):75-80. https://doi.org/10.1016/j.phpro.2011.03.010

41. Jiang M, Chen X, Chen Y, Tao W (2019) Increasing keyhole stability of fiber laser welding under reduced ambient pressure. $\mathrm{J}$ Mater Process Technol 268:213-222. https://doi.org/10.1016/j. jmatprotec.2019.01.026

42. Jiang M, Tao W, Chen Y, Li F (2019) Comparison of processing window in full penetration laser welding of thick high-strength steel under atmosphere and sub-atmosphere. Opt Laser Technol 109: 449-455. https://doi.org/10.1016/j.optlastec.2018.08.023

43. Romminger V, Haug P, Speker N, Holzer M (2013) High-power full penetration welding behavior. Laser Tech J 10(3):36-40. https://doi.org/10.1002/latj.201390036

44. Bunaziv I, Frostevarg J, Akselsen OM, Kaplan AFH (2018) Process stability during fiber laser-arc hybrid welding of thick steel plates. Opt Lasers Eng 102(Supplement C):34-44. https://doi.org/10. 1016/j.optlaseng.2017.10.020

45. Eriksson I, Powell J, Kaplan A (2013) Guidelines in the choice of parameters for hybrid laser arc welding with fiber lasers. Phys Procedia 41:119-127. https://doi.org/10.1016/j.phpro.2013.03.059

46. Frostevarg J, Kaplan A (2014) Undercut suppression in laser-arc hybrid welding by melt pool tailoring. J Laser Appl 26(3). https:// doi.org/10.2351/1.4872062

47. Tsukamoto S, Sugino T, Nakamura T, Arakane G Fundamental study on welding phenomena in pulsed laser-GMA hybrid welding. In: 24th International Congress on Applications of Lasers and Electro-Optics (ICALEO), Miami, Florida, USA, 2005. Laser Institute of America, pp 108-116

48. ISO 6507-1 (2018): Metallic materials - Vickers hardness test - Part 1: Test method.

Publisher's note Springer Nature remains neutral with regard to jurisdictional claims in published maps and institutional affiliations. 